\title{
Colorectal Cancer Disease in Appalachia: Symptom Interpretation and Cancer Worry Predictors
}

Omar F.S. Attarabeen

West Virginia University

Follow this and additional works at: https://researchrepository.wvu.edu/etd

\section{Recommended Citation}

Attarabeen, Omar F.S., "Colorectal Cancer Disease in Appalachia: Symptom Interpretation and Cancer Worry Predictors" (2013). Graduate Theses, Dissertations, and Problem Reports. 3607.

https://researchrepository.wvu.edu/etd/3607

This Thesis is protected by copyright and/or related rights. It has been brought to you by the The Research Repository @ WVU with permission from the rights-holder(s). You are free to use this Thesis in any way that is permitted by the copyright and related rights legislation that applies to your use. For other uses you must obtain permission from the rights-holder(s) directly, unless additional rights are indicated by a Creative Commons license in the record and/ or on the work itself. This Thesis has been accepted for inclusion in WVU Graduate Theses, Dissertations, and Problem Reports collection by an authorized administrator of The Research Repository @ WVU. For more information, please contact researchrepository@mail.wvu.edu. 
Colorectal Cancer Disease in Appalachia: Symptom Interpretation and Cancer Worry Predictors

Omar F.S. Attarabeen, B.Sc. Pharm.

\author{
Thesis submitted to the \\ School of Pharmacy \\ at West Virginia University \\ in partial fulfillment of the requirements \\ for the degree of
}

Master of Sciences

in

Health Outcomes Research

\author{
Kimberly Kelly, Ph.D., Chair \\ Usha Sambamoorthi, Ph.D. \\ Kevin Larkin, Ph.D.
}

Department of Pharmaceutical Systems \& Policy

Morgantown, West Virginia

2013

Keywords: colorectal cancer, worry, Appalachia, symptom interpretation, health care access. 


\section{Abstract \\ Colorectal Cancer Disease in Appalachia: Symptom Interpretation and Cancer Worry Predictors}

Master's Thesis

\section{Omar F.S. Attarabeen}

In the Appalachian region, many cultural, religious, and psychological factors have been identified to affect health. These factors are expected to play a role in health disparities, such as higher rates of colorectal cancer (CRC) incidence and mortality. Appalachia-specific factors such as geographic isolationism, poverty, and Appalachian stereotypes have been reported to negatively affect preventive health care including CRC screening. Although previous research has investigating the impact of some of these Appalachia-specific factors on seeking health care, impact of symptom interpretation and psychological states of the Appalachian population on health care seeking behavior needs to be clarified.

The objective of this study was to identify Appalachians' knowledge, health care seeking behavior, and emotions with regard to CRC. The focus in this study was on two main issues. First, the study investigated appraisal delay due to incorrect symptom interpretation (not inferring illness when experiencing symptoms) and thoughts and feelings about CRC. These points are discussed in manuscript \# 1 . Second, due to the heavy influence of psychological state on health behavior, manuscript \# 2 examined of the impact of perceived health, fatalism, religiosity, access to health care, and other demographic, cultural, and psychological variables on CRC worry.

A qualitative analysis [Manuscript \#1] was conducted on a sample of Appalachian men to explore their thoughts and feelings about CRC, appraisal delay, and symptom interpretation. The investigation of men's perspective in this manuscript was due to the greater likelihood for men to undergo CRC screening as compared to women (Seeff et al., 2004). The investigation of these points enabled determining the uniqueness of the Appalachians' health seeking behavior. Using a cross-sectional pilot study design, fifteen men above the age of 50 were interviewed. Interviews included semi-structured audio-taped recordings. Interviews were transcribed and analyzed through utilizing constructionism as an epistemology. Further, due to the fact that women report CRC worry more frequently than men do (McQueen, Vernon, Meissner, \& Rakowski, 2008), a sample of Appalachian women was surveyed in the second part of this study [Manuscript \# 2] in order to collect demographic, cultural (e.g., fatalism and religiosity), and psychological (e.g., $\mathrm{CRC}$ worry and general mood) quantitative data. The purpose was to investigate factors that were associated with CRC worry. The sample for this manuscript included 137 women who were at least 18 years old at the time of the study. The study was based on a cross-sectional structured mail survey. The epistemology utilized in this manuscript was objectivism. Participants for both manuscripts had no personal history of CRC. The Self-regulation Model (Leventhal et al., 1997) was utilized in both manuscripts to guide analysis. 
Findings from the qualitative analysis [Manuscript \# 1] on Appalachian-specific barriers to seeking healthcare showed that powerlessness was a common thought among many participants. Most participants indicated that the presence of barriers to seeking health care barriers that participants had no ability to control or fix - was the reason for not adhering to recommended screening guidelines. Symptoms interpretation, and consequently referring an illness, was variable among participants. However, the presence of (1) Severe symptoms that negatively impact the functionality of the body or (2) persistent symptoms that last for a long period of time were the most two important symptom-related cues to seeking health care. Results from the analysis on CRC worry [Manuscript \# 2] suggested that the following factors were associated with CRC worry: Higher education, greater magnitude of perceived absolute risk, tension/anxiety, and uncertainty about the access to health care.

In conclusion, manuscript \# 1 indicated that unawareness about health insurance programs, mistrust about health care providers and medical procedures, not having access to health care, and health illiteracy were some of the factors that influenced people's health care behavior. Some thoughts have not been reported in the literature. Example are letting symptoms "take care of themselves" and asking "old folks" instead of seeking care from health professionals, thinking about $\mathrm{CRC}$ as a stigma, and believing that it was socially inacceptable to talk about CRC-related issues. Manuscript \# 2 confirmed what previous research has found about the effect of education and absolute perceived risk for developing CRC on CRC worry, and suggested two other factors (perceived easiness of access to gastroenterologists and increased scores on the tension-anxiety sub-scale of the Profile of Mood States instrument) that were associated with CRC worry among Appalachian residents.

The use of mixed methods [qualitative and quantitative] in this study helped not only in identifying statistics regarding health beliefs, but also in clarifying the reasons for certain beliefs and behaviors among the Appalachian residents. The use of qualitative methodology helped in clarifying the uniqueness of the Appalachian population regarding health beliefs and health behavior. Results of this study will aid in designing more targeted interventions in the future, which will help Appalachian residents follow health care professionals' recommendations, and then, have better health care outcomes. 
Correspondence regarding this Thesis may be addressed to:

Omar F.S. Attarabeen, Department of Pharmaceutical Systems \& Policy, School of Pharmacy, West Virginia University. PO Box 9500. Morgantown, WV 26506-9500.

Email: attarabeen@gmail.com

This research study was funded by the National Cancer Institute (grant \# 5P50-CA105632-02). 
Table of Content

Page Number

Cover Title i

Abstract ii

Introduction $\quad 1$

Manuscript \# 1

Manuscript \# $2 \quad 43$

Summary $\quad 56$

References $\quad 59$ 


\section{Introduction to Both Manuscripts}

\section{Colorectal Cancer (CRC)}

$\mathrm{CRC}$ is the type of cancer that starts in the tissues of the colon or rectum. According to the American Cancer Society, CRC is the third leading cause of cancer related death in the United States, and the second leading cause when both genders are combined (American Cancer Society, 2013). In 2013, the number of estimated new cases is expected to be 142,820 , and the number of estimated death cases is 50,830 (American Cancer Society, 2013). These are alarming numbers considering that $\mathrm{CRC}$ is a highly preventable type of cancer if screening guidelines are followed (Levin et al., 2008; U.S. Preventive Services Task Force, 2008). Screening for CRC does not only help to detect early cancerous tissues in the colon and rectum, but also it helps to discover pre-cancerous polyps that can be removed before they may result in cancer. The potential for cancer prevention supports the importance of adhering to guideline-recommended screening procedures and health care providers' recommendations to engage in screening.

\section{Colorectal Cancer Screening}

The U.S. Preventive Services Task Force (USPSTF) (U.S. Preventive Services Task Force, 2008) recommends CRC screening for adults starting at the age of 50 using: (1) annual screening with high-sensitivity fecal occult blood testing (FOBT), (2) sigmoidoscopy every 5 years, with high-sensitivity FOBT every 3 years, or (3) screening colonoscopy every 10 years. However, the USPSTF recommends against routine screening for adults 76 years old and older, and health care professionals are charged with deciding the necessity for screening based on individual patients' needs. Other groups such as the American Gastroenterological Association and the American Cancer Society also suggested other screening tools such as fecal 
immunochemical test, stool DNA test, air-contrast barium enema, double-contrast barium enema, and CT colonography (virtual colonoscopy). However, the USPSTF guidelines have concluded that only the three previously mentioned screening tests (annual FOBT, sigmoidoscopy every 5 years and FOBT every 3 years, and colonoscopy every 10 years) have shown enough evidence that the benefits of screening outweigh the potential harms associated with screening (U.S. Preventive Services Task Force, 2008).

Adhering to CRC screening guidelines is important regardless of the presence of gastrointestinal symptoms associated with the disease, as patients with CRC disease may be asymptomatic (Lieberman et al., 2000). Thus, patients may not experience any symptoms until the cancer is at an advanced stage. As a result, following guidelines for CRC screening (Levin et al., 2008; U.S. Preventive Services Task Force, 2008) is essential regardless of the presence of any symptoms patients may experience to cue their decision about seeking screening. Thus, individual beliefs about the association between symptoms and the need for CRC screening may be problematic as some elderly may mistakenly believe that screening for CRC is needed only when symptoms present.

\section{Colorectal Cancer Diagnosis}

When patients do not adhere to screening guidelines, they are at greater risk of developing $\mathrm{CRC}$, which may grow into advanced stages before symptoms are noticed. As a result, patients may not begin noticing a change in their bowel habits, or experiencing other symptoms, until they have late stage cancer. Yet, even when CRC screening guidelines are properly followed, there is still a chance - a significantly lower chance compared to not screening - of having an aggressive form of the disease that develops quickly and is at an 
advanced stage before the next scheduled screening appointment, an interim cancer. Thus, regardless of whether or not a person is appropriately screened, reporting symptoms to health care providers as soon as a patient becomes aware of having symptoms is critical.

Literature has shown the importance of appraisal delay - delay from symptom onset until interpreting the symptom as potentially dangerous - in prolonging the time period between noticing symptoms and seeking health care (Safer, Tharps, Jackson, \& Leventhal, 1979), especially when it comes to cancer care (Andersen, Cacioppo, \& Roberts, 1995). Taking into account other types of delays (e.g., behavioral delay, scheduling delay, treatment delay), the literature has shown that appraisal delay is the most important type of delay, since it alone accounts for $60 \%$ of total delay in care seeking (Andersen et al., 1995). As a result, health care providers and policy makers should work to shorten appraisal delay, as appraisal delay is the ideal type of delay to be modified by increasing patients' awareness and knowledge. Considering the morbidity and mortality of CRC noted above, patients' interpretation of symptoms and the importance of taking action by being vigilant and seeking health care is essential in avoiding detrimental outcomes. Examination of factors influencing appraisal delay is critical for exploring why individuals do not engage in screening for CRC, and these factors may be even more important when examining reasons why individuals in medically underserved communities do not engage in screening. One important community of interest for examining health disparities like those associated with CRC screening is inhabitants of Appalachia.

\section{Appalachia}

Appalachia is a geo-politically defined region that extends over 13 states and includes about 25 million people or $8.2 \%$ of the U.S. population (Pollard \& Jacobsen, 2013). 
Appalachians may share common cultural, religious, and psychological characteristics. A 2011 study has reported low educational attainment in the Appalachian region, where it was found that rates of college graduation and advanced degree attainment is about half the rate of the rest of the nation, which in turn, may reflect upon their income levels (Bollinger, Ziliak, \& Troske, 2011). Hendryx et al. (2011) found that the poverty rate in some localities in Appalachia is associated with an elevated mortality rate, indicating a health disparity. The Appalachian population is predominantly composed of those of White race, with $83.6 \%$ of the Appalachian population being Non-Hispanic White compared to $63.7 \%$ of Non-Hispanic Whites in the US population. The representation of minorities in Appalachia is less than the national average; Blacks are 9.1\% (U.S. 12.2\%) and Hispanics are 4.2\% (U.S. 13.6\%) (Pollard \& Jacobsen, 2011).

It is expected that health behaviors of Appalachians reflect their beliefs and views concerning health issues such as CRC. Primary care physicians working in Appalachia have reported that certain beliefs: such as a fatalistic view of cancer and certain religious beliefs, are barriers to performing cancer screening (Shell \& Tudiver, 2004). These cultural beliefs are not biological traits. They may be defined by what people adopt in their lifetime or take from their societies. Moreover, cultural and psychological beliefs are not innate; they are what people embrace as a way of life from their families, societies, environment, and other people (Edberg, 2007). For example, what people define as healthy versus unhealthy, influences eating habits, exercise practices, and many health-related behaviors such as CRC screening (Edberg, 2007).

Despite previous research and interventions conducted in the Appalachian region, additional research is needed to understand how culture, religion, and other demographic and psychological variables play a role in health behavior (Behringer \& Friedell, 2006; Coyne, Demian-Popescu, \& Friend, 2006b; Diddle \& Denham, 2010; Rowles, 1991; Shell \& Tudiver, 
2004; Vanderpool \& Huang, 2010). Appalachians, especially in rural areas, suffer from significantly higher mortality from colorectal cancer (CRC) than the U.S. population (Blackley, Behringer, \& Zheng, 2012; Fisher et al., 2012; Huang, Wyatt, Tucker, \& Bottorff, 2002). Although many studies have explored CRC screening in Appalachians (Armstrong et al., 2004; Bardach, Schoenberg, Fleming, \& Hatcher, 2011; Curry et al., 2011; Davis, Armstrong, Dignan, Norling, \& Redmond, 2006; Hopenhayn et al., 2004; Kelly et al., 2007; Lengerich, Rubio, Brown, Knight, \& Wyatt, 2006; Paskett et al., 2013; Reiter et al., 2013; Spitler, Mayo, \& Parker, 2001; Tarasenko \& Schoenberg, 2011; Tarasenko, Fleming, \& Schoenberg, 2013; Tessaro, Mangone, Parkar, \& Pawar, 2006; Ward, Coffey Kluhsman, Lengerich, \& Piccinin, 2006), the associations of culture, religion, worry and CRC screening have been understudied. For purposed of this study, a theoretical foundation proposed by Leventhal and colleagues (1997), the Selfregulation Model (SRM), was employed.

\section{Theoretical Framework: Self-Regulation}

The Self-regulation Model (SRM) (Leventhal et al., 1997) is a process model that aims to explain the way people behave with regard to their health. This model assumes that when individuals are affected by an emotional drive (affective representation) associated with threat to one's health caused by a disease (cognitive representation-, individuals may opt to engage in health behaviors (including CRC screening) in order to reduce the emotional drive, especially when a clear and effective action plan to avoid threats associated with disease onset is available (Leventhal, Diefenbach, \& Leventhal, 1992). This model has been utilized in the literature to explain people's behavior in response to a threat that endangers their health and guide how they cope with such threats. In this particular context, the SRM enabled us to understand (1) the factors pertaining to adherence to CRC disease screening, (2) the reactions of patients to the 
threat of CRC by regularly screening for the disease, (3) the decision to seek medical care when they experience relevant symptoms, or (4) the CRC worry that may affect their health related behavior.

The SRM model combines self, social environment, cognitive and affective representations, health behaviors, and perceived effectiveness of coping mechanism to manage the threat (Leventhal, Brisette, \& Leventhal, 2003b). As shown below in Figure 1, these components influence each other in a way through which health behavior is balanced with appraisal (perceived effectiveness of the action plan pursued in order to avoid the health threat). This model helps us to understand individual's perceptions about CRC as a threat. Thus, it aids in identifying Appalachians' views about symptoms that might suggest colorectal disease involvement, and their views about CRC-related factors that affect the degree of CRC worry they might have. By using the SRM, we can clarify the psychological thoughts underlying symptoms reported to physicians and CRC-related worry.

Self-regulation can be presumed as a mechanism patients utilize to control their health, for instance by avoiding the health threat or by seeking an ideal body state (Scheier \& Carver, 2003). The model assumes that patients act as active problem solvers in order to reach goals patients have in mind (e.g., avoid cancer-related worry), especially when positive and achievable behavior outcomes are expected. Thus, patients continuously monitor their actions and compare them with pre-determined set of criteria (e.g., ideal body). They make this comparison in order to eliminate the anxiety or the worry they may have regarding the health threat when their actions match those criteria. Otherwise, patients will experience anxiety or worry if their actions (i.e., behavior) do not lead to the goals they have set, or when steps to reach the ideal state are not being undertaken. 


\section{Cancer Worry}

Leventhal et al. argued that emotional representation (e.g., cancer worry) is capable of generating health behavior (e.g., engagement in cancer screening) only when associated with a clear action plan (Leventhal, Brisette, \& Leventhal, 2003b). For example, interventions based on the SRM aiming to increase people's adherence to CRC screening guidelines should include an affective factor (e.g., increasing cancer worry) along with a clear description of what people can do (i.e., action plan) and why (i.e., cognitive representation) they should follow the screening guidelines. Consequently, the individual is expected to behave in a way in order to reduce cancer anxiety and control or eliminate that health threat. A clear action plan should explain when and where screening might be done in order to avoid the fear of cancer or cancer worry.

Cancer worry is a critical component of the SRM as it is applied to CRC. Cancer worry is defined as the emotional reaction to the threat of cancer (Bowen et al., 2003; Kirscht, Haefner, Kegeles, \& Rosenstock, 1966), and as the definition suggests, it is a psychological reaction to a negative health event, such as the threat of having cancer. Cancer worry may motivate additional behavior such as screening or seeking health care. For many years, there have been concerns that some racial/cultural groups experience cancer worry more intensely than the general population (Aiken, Gerend, \& Jackson, 2001). Thus, Appalachians, especially people in rural Appalachia, may also be at risk of having more cancer worry than the general population. From a theoretical point of view, cancer worry is a critical and influential variable. For example in the SRM, cancer worry may provide a cue to action for engagement in cancer screening. In other words, whenever patients are more worried about CRC, they may tend to adhere more strictly to CRC screening guidelines in order to avoid having the disease. 
However, our understanding of cancer worry itself is limited. Factors associated with cancer worry have not been investigated thoroughly in the literature. Some studies have found that increased perceived comparative risk (perceived risk in comparison to other people: lower, same, or higher) and increased perceived absolute risk (perceived universal risk in percentage or in general: likely or unlikely to get $\mathrm{CRC}$ ) are possible predictors of elevated cancer worry (Lipkus et al., 2000; Zajac, Klein, \& McCaul, 2006). Although the literature has shown that both perceived absolute and comparative risk are significant predictors of general cancer worry, perceived absolute risk was found to be a better predictor of general cancer worry for women than men (Zajac et al., 2006). Other factors such as trait anxiety (Price, Butow, Lo, \& Wilson, 2007) and family history of cancer (McCaul, Branstetter, O'Donnell, Jacobson, \& Quinlan, 1998) were predictors of cancer worry in a sample of women from high risk breast cancer families.

\section{Colorectal Cancer Worry}

Even less data is available about the factors associated with CRC worry. Demographic factors may be important factors in CRC worry, such as gender. One study that utilized nationally representative data (HINTS, 2003) showed that women expressed more cancer worry than men. However, cancer worry was lowest in both genders for CRC in comparison to other kinds of cancer (McQueen, Vernon, Meissner, \& Rakowski, 2008). Further, Collins et al. found that colon cancer worry was positively associated with higher education level and younger age (Collins, Halliday, Warren, \& Williamson, 2000).

Perceived risk of CRC is another important factor that contributes to CRC worry. Consistent with the findings regarding general cancer worry, perceived absolute and comparative risk perceptions were found to be significant predictors of colon cancer worry in both men and 
women. Moreover, Hay, Coup, and Ford (2006) found a direct correlation between colon cancer worry and both perceived comparative and absolute risk in participants who had poorer selfreported health than average. Vernon, Myers, Tilley, and Li (2001) found a positive association between absolute perceived risk and worry about being diagnosed with CRC in men with and without personal history of polyps. Also, among individuals who were highly depressed, only comparative risk perception predicted colon cancer worry, but perceived absolute risk did not (Zajac et al., 2006). Finally, Collins et al. (2000) found that colon cancer worry was positively associated with higher comparative perceived risk of CRC. Based upon the literature in this area, the following hypothesis was proposed for manuscript \# 2:

Hypothesis 1: We hypothesized that people who perceive their CRC risk (both comparative risk and absolute risk) to be higher were more likely to express CRC worry than those who perceived lower risk.

\section{Colorectal Cancer Screening and Worry}

Literature investigating the association between cancer-associated worry and screening for cancer has produced conflicting results (Hay, Buckley, \& Ostroff, 2005), with some empirical studies finding that cancer-associated worry was a barrier to screening (Champion, 1988; Hill, Gardner, \& Rassaby, 1985; Miller \& Champion, 1993; Watts, Vernon, Myers, \& Tilley, 2003), and some empirical studies finding that cancer-associated worry facilitated screening (Cameron, Leventhal, \& Leventhal, 1995; Diefenbach, Miller, \& Daly, 1999; Hay, McCaul, \& Magnan, 2006; McCaul, Schroeder, \& Reid, 1996; McCaul et al., 1998). However, all of these empirical studies have investigated cancer-associated worry and screening that pertained to other types of cancer (e.g., breast cancer) rather than CRC. The association between 
CRC screening and cancer worry is understudied in the literature. Only one study has examined the relation between CRC worry and screening, and no relations were observed (Brenes \& Paskett, 2000). However, flexible sigmoidoscopy was the only screening outcome measured in the study. Thus, the literature supports both positions that worry related to cancer may act as a barrier or facilitator to adhering to health care guidelines, with a number of articles supporting these two competing positions.

\section{Cancer Worry: Theoretical Studies}

In addition to empirical studies, some theoretical papers have posited an association between cancer worry and health behavior, with some suggesting worry serves as a facilitator of screening (Diefenbach \& Leventhal, 1996; Leventhal, 1970; Leventhal \& Cameron, 1987), and others suggesting worry parallels the cognitive representation of danger (disease threat). According to this latter perspective, this cognitive representation of danger does not translate into healthy screening behavior unless a clear and protective action plan exists. However, in the presence of such an action plan, the cognitive representation is suggested to have a dosedependent effect of health behavior depending on the individual's perceived health threat (Leventhal et al., 1997). A study by Robberson and Rogers (1988) has found that worry may facilitate positive health behaviors only in the presence of other important psychological determinants such as self-esteem [overall emotional evaluation of self-worth (Blascovich \& Tomaka, 1991)] or self-efficacy [personal judgments of one's capabilities of functioning (O'Leary, 1985)]. Other theoretical papers suggested the same positive linkage between cancer worry and screening, with self-esteem or self-efficacy being significant moderators (Rogers, 1983; Witte, 1992). For example, Witte (1992) indicated that perceived threat may elicit protective and adaptive responses if both threat and self-efficacy are perceived as high. 


\section{Colorectal Cancer Fatalism}

Fatalism has been discussed as a factor in Appalachian culture that may affect health behavior (Behringer \& Krishnan, 2011; Coyne, Demian-Popescu, \& Friend, 2006a; Lewis \& Billings, 1997; Royse \& Dignan, 2001; Shell \& Tudiver, 2004; Vanderpool \& Huang, 2010), such as in cancer screening. Fatalism, "the belief that an individual's health outcome is predetermined or purposed by a higher power and not within the individual's control" (Franklin et al., 2007), has been identified as a barrier to CRC screening and other preventive behaviors for many populations such as Hispanics (Fernandez et al., 2007; 2008; Gorin, 2005; Monteros \& Gallo, 2011; Natale-Pereira et al., 2008; Powe et al., 2009; Shelton, Jandorf, Ellison, Villagra, \& DuHamel, 2011) and African Americans (Greiner, Born, Nollen, \& Ahluwalia, 2005; Morgan, Tyler, \& Fogel, 2008; Philip, DuHamel, \& Jandorf, 2010; Powe, 1995; Sanders Thompson, Lewis, \& Williams, 2011; Smith-Howell et al., 2011). Moreover, the effect of pessimistic/fatalistic thinking on cancer screening in general has been studied in the Appalachian region (Royse \& Dignan, 2001). However, the previous literature did not clarify the impact of fatalistic beliefs on CRC worry in Appalachia. Since people who score higher in fatalism typically perceive cancer as equivalent to death (Powe \& Finnie, 2003), we expected that they would be more likely to worry about the disease. As such, the following hypothesis was proposed for manuscript \# 2:

Hypothesis 2: We hypothesized that people who score higher in fatalism would be more likely to express CRC worry than those who scored lower on fatalism.

\section{Colorectal Cancer and Religion}


Previous research has suggested that holding fatalistic beliefs is more influential on health when associated with religious beliefs (Franklin et al., 2007). Yet, religion was independently suggested as in important factor that plays a significant role in Appalachian behaviors (Photiadis, 1977). Researchers in Appalachian culture and health have suggested the importance of religion and spirituality in decision making regarding health care, especially cancer care (Behringer \& Krishnan, 2011). Data has supported the beneficial impact of attending religious activities on health and survival (Strawbridge, Shema, Cohen, \& Kaplan, 2001), decreasing mortality (McCullough, Hoyt, Larson, Koenig, \& Thoresen, 2000), protecting healthy people against death (Powell, Shahabi, \& Thoresen, 2003), increasing physical activity (Kim \& Sobal, 2004), and helping people to cope with stress and depression (Lewis \& Billings, 1997). However, literature was scant regarding relations between cancer worry and religiosity. A study conducted on prostate cancer patients showed that patients with higher levels of cancer worry were more likely to report increased religiosity (Hamrick \& Diefenbach, 2006). Despite this finding, the bulk of research about the connection between attending religious activities and survival indicates decreased mortality (McCullough et al., 2000), increased protection against death (Powell et al., 2003), and increased physical activity (Kim \& Sobal, 2004). Thus, we expect that religious commitment helps patients to cope with stressful conditions and makes them more likely to have a stable and healthy life, with less fear and anxiety about the future. In summary, we proposed the following hypothesis for manuscript \# 2 regarding the impact of religious commitment on cancer worry:

Hypothesis 3: We hypothesized a negative relation between religious commitment and cancer worry, such that people who scored higher in religious commitment scale were less likely to have CRC worry than those who scored lower in religious commitment. 


\section{Colorectal Cancer Related Worry and Health Care Access}

Whenever patients have more difficulty seeing a gastroenterologist, or any physician who can perform or advise in regard to CRC screening, patients may be more worried about getting the disease in the future and more anxious whenever it is time for their next screening appointment. Lack of health insurance might create a state of distress for people who cannot afford to pay for their health care. A study by Keeler et al. (1987) investigating the impact of cost sharing on psychological state found that people with cost sharing had less worry from physiological conditions to which they were exposed. Thus, we expect that people who live in isolated or rural localities, like many Appalachians, may express more cancer worry because of limited access to health care due to economic difficulties, or geographic isolation. Based upon this position, the following hypothesis was proposed for manuscript \# 2:

Hypothesis 4: We hypothesized that people who had limited access to health care were more likely to express CRC worry than those who had greater access.

\section{Manuscript \# 1}

\section{Introduction}

Previous research has indicated the high mortality rate due to $\mathrm{CRC}$ in the Appalachian region in comparison with other regions in the U.S. (Blackley et al., 2012; Fisher et al., 2012; Huang et al., 2002). This indicates a need for addressing the way people in Appalachia think of CRC (i.e., their cognitive representation) and the emotions and feelings they have with regard to the disease itself and to its screening (i.e., their affective experience). The study of these cognitive and affective factors along with self-system factors (e.g., self, demographics, and social environment) may help in the prediction of people's health behavior, especially preventive 
behavior like screening for CRC. The literature lacks information about CRC symptom interpretation, CRC screening knowledge, and health literacy pertaining to CRC among people who live in the Appalachian region. Differences among these variables may exist in this distinctive cultural group and knowledge of these differences is important for studying health literacy of Appalachian residents.

Due to significant poverty and geographic isolation that exist in the Appalachian region (Duncan, 1992), combined with widespread unawareness about preventive care in general and CRC screening guidelines in particular, reducing CRC mortality might be more challenging in Appalachia than it is elsewhere. Barriers to healthy behavior, seeking preventive health care, and attitudes regarding CRC screening uptake need to be addressed in order to identify the factors that may lead to the health disparity in CRC prevalence documented among the Appalachian population (Lane, Lutz, \& Baker, 2012). Identifying feelings and emotions people have regarding CRC and its screening, cognitive representation of CRC, and self-system related factors may help in predicting health behavior, and consequently, in designing future interventions that aim to eliminate or reduce the health disparity in this region. The purpose of the qualitative study was to investigate thoughts and feelings of Appalachian residents about CRC and CRC screening, and investigate perceived knowledge about symptoms.

\section{Participants}

All participants in this study were residents in the Appalachian region in the state of Ohio. Participants were recruited through advertisements at senior centers inviting them to participate by calling a $1-800$ phone number, mail solicitations, or re-contact after participating in previous research and showing willingness to be further contacted for future research. 
Although females were included in the larger study, the sample used in this qualitative study included only 15 male participants, because few of the female participants were 50 years of age or older. All participants in the current analysis were at least 50 years old at the time of interviewing and had no personal history of CRC. Participants were divided into two groups: screeners and non-screeners. Screeners $(n=3)$ consisted of men who had been adherent to CRC screening guidelines at the time of the interviews, whereas non-screeners were men who never engaged in any CRC screening behavior or showed non-adherence to CRC screening guidelines $(n=12)$ at the time of the interviews.

\section{Procedures}

The current study utilized archived data from a cross-sectional pilot study [Grant \# 5P50CA105632-02. PI: Kelly, K.] that included a written questionnaire and an audiotaped, semistructured interview. Institutional Review Board (IRB) approval was obtained from study participants. Recruitment included directly approaching participants in local clinics or sending a letter inviting participants who participated in research previously and were willing to be contacted for future research. Eligibility was determined by the interviewer or the research assistant. Each interview started with signing an informed consent agreement, followed by a brief written questionnaire (Appendix 2). Items in the questionnaire included demographics, perceived health, and tobacco and alcohol consumption. Demographic data included county of residence: to determine rural residence (United States Department of Agriculture, 2013) and confirm Appalachian residence (Appalachian Regional Commission, 2013). After completing the questionnaire, a semi-structured interview was conducted (Appendix 2). Time to complete the study was approximately 1 hour and participants received $\$ 20$ for their time. 


\section{Questions}

The semi-structured interview, which is the main focus of this manuscript, assessed key elements related to thoughts and feeling about CRC disease and CRC screening.

First, we investigated thoughts and feelings that participants had about CRC disease and CRC screening, and to what extent they believed in the effectiveness of screening for preventing the disease. We expected that using qualitative methods would not only clarify the impact of perceived efficacy of CRC screening, but also reveal the explanation behind people's behavior.

Second, we explored the perceived knowledge about symptoms of CRC disease and investigated the accuracy of knowledge people have regarding symptoms suggestive of CRC.

Semi-structured interviews were tape-recorded. They were transcribed into electronic files to facilitate analysis. Relevant ideas from the Self-regulation Model were extracted to develop a coding scheme (Appendix 1). Using line-by-line coding, codes were attached to relevant text. Codes were grouped in themes that are emergent from the text, as related to the Self-regulation Model.

\section{Plan of Analysis}

Qualitative Analysis. The epistemology inherent in the theoretical perspective for this manuscript was constructionism; a concept that states that truth is reached by our engagement into realities around us (Crotty, 1998). For instance, studying of CRC-related behaviors among Appalachian residents would be constructed by our engagement with this population and understanding of how people perceive it. The methodology used was immersion/crystallization, in which, the researchers immerse themselves in the data by examining the details thoroughly, and then temporarily suspending the immersion process to have an overall preview on the data 
and extract themes and general ideas from the data (Borkan, 1999). A useful advantage of immersion/crystallization is that it can be used with pre-existing theory.

The use of the Self-regulation Model (SRM) to investigate the questions posed earlier helped in revealing the psychological states behind the beliefs of participants, such as what they believe about the health threat. Depending on the self-system component of SRM, we expected that some participants' beliefs may originate from their social environment and culture. These beliefs affect how participants react toward health care professionals' recommendations, such as recommendations to undergo CRC screening (Baumann, 2003).

The cognitive representation component of SRM is represented by the health threat that participants may think endanger their well-being. This cognitive representation - also known as the Common Sense Model - underlies people's beliefs about what the specific health threat is, in this case, CRC. The representation of cognition is categorized into 5 attributes: (1) identity/label, (2) causes and risk factors, (3) timeline, (4) consequences, and (5) cure/control (Leventhal et al., 1992). This cognitive representation articulates the lay persons' perception on what the health threat is.

Participants' beliefs about the health threat may help indicate how they react towards $\mathrm{CRC}$ in the future. For example, if participants believe that CRC is preventable, they may be more likely to react to prevent it by engaging in recommended screenings and following health care recommendations.

The affective representation of the SRM is what people feel about the health threat. In our manuscript, the feelings about CRC or CRC screening fall into this category. It includes, but not limited to, fear, anxiety, and worry. The impact of this affective representation on health 
behavior has been a point of discussion among researchers. An example of this discussion was posited above; worry has been found to have a positive and/or negative impact on CRC screening. However, from the SRM point of view, where participants are deemed active problem solvers, we expect that a moderate amount of worry may provoke participants to seek health care in order to avoid the health threat.

In summary, the relation between worry and cultural variables is built on a theoretical model that incorporates self-system, cognitive and affective representations, health behavior, and appraisal variables. Ideas of how Appalachian culture may affect health behaviors, and how beliefs are translated into actions in society, are investigated by examining the various Selfregulation Model components.

Many items from the self-system, the Common Sense Model, and the affective representation components of the Self-regulation Model were compared between the screening group and the non-screening group. Next, the screening group and the non-screening group were compared for symptom interpretation to determine (1) if participants from different groups had different knowledge about CRC symptoms, and (2) if they had the same conceptions about the threshold of symptoms at which they felt the need to seek health care.

\section{Results}

Sample Characteristics. Participants $(n=15)$ were all males from rural Appalachian counties in Ohio. Rurality was determined from the Rural-Urban Continuum Codes (United States Department of Agriculture, 2013). Thirteen of the 15 participants (86.7\%) were of Caucasian race. One was of African-American race and another was of American Indian/Alaskan Native race. Participants' ages ranged from 50 to 72 years, with a mean age of 59 years. All 
participants were non-Hispanics. Although all participants were from an Appalachian county, only $46.7 \%$ of them considered themselves to be Appalachians. Regarding education, $40 \%$ of the participants had not attended college. About half of the participants (53.3\%) had an annual household income of $\leq \$ 10,000$. Most participants $(64.3 \%)$ perceived their health as Fair/Poor, whereas the rest (35.7\%) perceived their health as Good/Very good. The majority of participants (42.9\%) reported that they self-paid for their health care (i.e., had no health insurance), whereas the second most group (28.6\%) reported having Medicaid coverage. Most participants were nonsmokers $(85.7 \%)$, and reported not having alcohol in the past 30 days $(71.4 \%)$.

The Self-regulation Model. Responses were considered in terms of their overall fit with the Self-regulation Model. Responses were compared to determine differences between those who followed and those who did not follow CRC screening guidelines.

\section{Self-System}

Many sub-themes were identified through qualitative analyses regarding the Self-System, including: (1) demographic and innate factors, (2) familial, social, and/or cultural factors, (3) health care provision and health care system, (4) patient-physician communication, and (5) awareness and health literacy on explaining people's behavior with regard to CRC screening. Overall, the most critical feature of sub-themes was their focus on external factors that exhibited themselves as barriers, such as poor financial situation, structural barriers regarding access to care, social disabling influences, governmental neglect, and medical inappropriate settings of which people have little ability to control. As a result, most participants thought it was not in their control to have good health care, including pursuing screening for CRC. Each of the subthemes will be described in the sections that follow. 
(1) Demographic and Innate Factors. The most notable sub-theme in demographic and innate factors was the widespread poor income/poverty in rural Appalachia. Unemployment, low income, and not having access to health care were commonly reported barriers to health care by participants. This is understandable, as more than half of the participants had annual incomes of $\leq \$ 10,000$. Additionally, the experience of competing demands, such as having other diseases (e.g. heart problems) and/or having household related problems, made participants focus more on taking care of the issue-at-hand rather than trying to prevent future ones. Some participants reported enhanced well-being when not pursuing screening for the disease; for example, by knowing that they have the disease, will increase worry or force them to spend too much money on health care and be in debt. Thus, disengagement, which some may call 'fatalism,' was a prevalent attitude they adopted.

Despite the health care disparity documented in the Appalachian region (Lane et al., 2012), the shortage of primary care physicians (Stensland, Mueller, \& Sutton, 2002), and perhaps even the inability to afford a vehicle, participants did not mention transportation as a barrier to screening or seeking health care. Additionally, it was notable that participants did not mention time constraints (i.e., missing work due to time spent receiving health care) as a factor hindering them from seeking health care or screening for CRC. The latter finding might be explained by the fact that most participants $(64.3 \%)$ reported being unemployed, retired, or disabled.

Another important factor mentioned during the interviews was metro/non-metro area of residence, with one participant making a comparison between those from his area and those who grew up in cities. He said that unlike "city boys," people from his area "tend to let things take care of themselves." If that does not work, people find home remedies, and if home remedies do 
not work, the next step would be to "ask the old folks." This mentality contributed to a diagnostic, symptom-based mindset, rather than a preventive, screening mindset.

(2) Familial, Social, and/or Cultural Factors. Thinking about the procedures for CRC screening as socially inconvenient made some of the participants less adherent to screening guidelines. For example, feeling too embarrassed or too socially-constrained to engage in screening was a factor mentioned by some participants. One participant was described how some older women in the Appalachian region behave with regard to CRC screening. He quoted her saying, "Well, I am not going to do that [CRC screening], I am not letting no guy, I do not even let my husband go there." Building upon this perspective, the participant perceived that embarrassment was a big barrier in Appalachia, especially for women. Additionally, gender differences between the provider and the patient might result in an increased embarrassment. Further, another participant mentioned how stigmatized cancer is in the society, "It is distasteful, nobody wants to talk about it, nobody wants to say that they have it." Notably, this participant was from the non-screening group. He thought that it was socially unacceptable to even talk about CRC, a view that may partially explain the lack of knowledge participants had about CRC.

On the other hand, media aiming to increase the awareness of colorectal screening guidelines at the societal level may effectively influence people's behavior. One participant reported that societal awareness programs, such as television advertisements, addressed the importance of adhering to the guidelines and served as cues to following these guidelines. Another participant mentioned that religious and social gatherings might be appropriate opportunities to disseminate health related information, which may encourage people to seek health care. The effect of religion on health was mentioned as a positive factor toward the prevention of CRC. One participant implied that religious people were less likely to get cancer 
than non-religious people. He went on to express how surprised he was that a woman whom he knew was religious and died of cancer, "She was a very religious person, and we always wondered why did it hit her other than the fact that she was probably a bigger woman."

Regarding cues to engage in screening or seek health care, the support of family members, especially spouses, was a very important stimulus. For example, one participant remarked "I think people are ought to do it [CRC screening] if more wives push their husbands." Many participants thought that recommendations of family members and friends formed a strong impetus for them to adhere to guidelines and engage in screening when there were no symptoms. Another example was: "everybody had been on me about it, my brother, my friends ... It was like I knew I should have had it [CRC screening] done.” Having a family history of CRC was another stimulus to engage in screening and seeking preventive health care. Lastly, seeing acquaintances either dying from $\mathrm{CRC}$ or screening for the disease was another motivator that made people think and be concerned about their health and consequently motivate them to engage in screening even without the existence of any symptoms.

(3) Health Care Provision and Health Care System. Even those who had health insurance reported receiving inadequate health care. First, those who had governmental health insurance programs, such as Medicaid, reported receiving poor care in which they were treated in less than optimum way. For example:

They [health care professionals] fix one thing and that breaks another, and they say, "Well this guy is no good. These people are no good, they do not take care of themselves," and it is not really that, it is a rough way of life. 
This participant was describing his feelings of inferiority after receiving health care under the Medicaid program. Additionally, patients reported discomfort and inconvenience regarding the procedures and the preparation for the tests. For example, the preparation drink that is needed before the colonoscopy was one of the elements that colored the bad experience participants had about colonoscopy. Although such hurdles made participants think negatively about screening, no one mentioned that such factors were real barriers that prevented the participant from actually engaging in screening for CRC.

With regard to cues to seeking health care, such as screening for CRC, participants had similar views by believing that the availability of free or low cost screening programs would significantly improve their guideline-appropriate engagement in CRC screening. In addition, an educated public regarding the awareness of free/low-cost screening programs would increase patient demand, resulting in patients' requests for physicians to perform such services.

(4) Patient-Physician Interaction. Many participants had similar views that doctors' recommendations were an important predictor of whether patients participated in screening for CRC. Some participants thought that health care professionals (1) are neither trustworthy nor serious in finding a cure for CRC and (2) need more education on how to communicate with patients and respect them.

Physician Trustworthiness. A participant from the non-screening group thought he should seek health care only if there is a major problem that negatively impacts his physical functioning. He thought that he should not go to see health care professionals or seek health care unless there is a clear, overwhelming problem where the chance of misdiagnosis is minimal, and 
consequently, the chance of having unnecessary health care procedures is as low as possible. He states: "I have always had the feeling if they look hard enough they are going to find something."

Some participants mentioned mistrust they have about some types of healthcare professionals. One participant believed that books on health and nutrition were not reliable to follow, by saying "The answer to me was to buy a book on how to lose weight and just do the opposite." Another participant believed that drug manufacturing companies and health care professionals did not want to cure CRC; rather they wanted to keep treating it as a chronic condition to make more money. Compared to industrial researchers, this participant believed that academic researchers were the ones who are likely to find a cure. According to this participant, industrial researchers do not want to find a cure; they just want to find a treatment that creates a permanent incurable condition in order to guarantee everlasting earnings of financial profits out of patients' pockets.

Physician Approach. Inappropriate 'bed-side manner' was noted by some participants, perhaps indicating poor quality of care. A patient was describing his dissatisfaction with health care professionals, by saying "They treat you like a piece of trash. He [the doctor] came up and started poking me and stuff, and not telling me what he was doing and I do not like that, I am a full grown man."

(5) Awareness and Health Literacy. Another theme from the interviews was the role of awareness and education in screening among Appalachian population. Many participants were unaware of CRC screening guidelines, the nature of procedures done, and/or different types of screening tests. Once participant thought he was not following the CRC screening guidelines. However, after being probed by the interviewer, it was revealed that he was following the 
guidelines. This may have indicated lack of health literacy as he neither knew the names of these tests nor how often they should to be done. This case was the opposite of what previous research has found, where more people thought they were following the guidelines than they really did (Reiter et al., 2013).The majority of participants did not have any experience at all with screening, although all were over 50 years old and should have had undergone at least one screening procedure. One participant had a very socially-minded view of Medicaid/Medicare. Although he was dually eligible for Medicaid and Medicare, he did not pursue cancer screening for fear of overtaxing the Medicaid/Medicare systems. He commented:

I would bet this thing [free health care] will be terminated. They will go on with it for a couple of years and then they will say 'it's too much money and it's not doing enough good'. I don't want to throw a chill on it ... because they will take this away, it's too nice.

Although the participant had a genuine intention toward saving the government money, he did not realize that treating $\mathrm{CRC}$ disease costs much more than preventing it.

Many participants did not know when they should start screening, how frequently they should screen for CRC, and where to go in order to have such screening tests. One of the participants indicated that he talked with the doctor, but the doctor did not mention screening to him. He went on to say: “I think it is blood work and stuff like that, isn't it?" This 64-year old participant who never had CRC screening thought that screening is done by blood test, with a sample of blood taken from the veins, perhaps an indicator of lack of effective patient-physician communication or a complete lack of patient-physician communication.

\section{Common Sense Model}


Individuals reported many thoughts about CRC that enabled classification into attributes related to the Common Sense Model (also known as cognitive representation of the SRM). These attributes articulate the representation of health threat from the lay people's viewpoint (Leventhal et al., 1992). This model addresses how perceived cognitive representation about the disease influences the coping mechanism pursed in order to avoid it (Leventhal, Meyer, \& Nerenz, 1980). The attributes are (1) identity/label, (2) causes and risk factors, (3) timeline, (4) consequences, and (5) cure/control. These attributes are discussed below with regard to CRC as extracted from the semi-structured interviews.

(1) Identity/Label of CRC. Some participants, especially from the non-screening group, thought that CRC symptoms are the same as the symptoms of fissures, hemorrhoids, typhoid, or diabetes. Therefore, they thought that if they experienced such symptoms, they would make the assumption that more common diseases may present or presumed it to be complications of current health conditions, rather than referring to the likelihood of getting CRC. Although many participants believed that $\mathrm{CRC}$ could be asymptomatic until it is in late incurable stages, some participants mentioned diarrhea, constipation, continuous bleeding, rectal bleeding, pain, and anemia as CRC symptoms. It was notable that no one mentioned other actual symptoms of CRC such as unexplained weight loss, weakness or fatigue, and feeling that the bowel does not empty completely (American Gastroenterological Association, 2013b). Also, the belief that only persistent symptoms necessitated seeing a physician overlaps with previous research studying the Appalachian population (Tessaro et al., 2006).

Some participants did not link presence of polyps to CRC. This may indicate that such those participants were less likely to know that polyps may develop into cancer if not removed, which may render them more vulnerable to the disease as they do not take action to prevent CRC 
by detecting and removing polyps. Additionally, some participants had some misunderstanding of how symptoms related to the disease. For example, one participant stated: "I have never seen any blood down there, so I knock on wood!” This participant thought that having no colonrelated symptoms means being safe from CRC.

(2) Causes and Risk Factors. Participants talked about two major categories of causes and risk factors for CRC: modifiable and non-modifiable causes and risk factors. Talking about the modifiable causes and risk factors, participants had variable views about some points. For example, although many participants thought that smoking was a cause of CRC, one participant claimed that quitting smoking was another problem because it led to obesity, which was a risk factor for CRC. Other modifiable risk factors mentioned were low physical activity and not washing products bought from the market. Participants thought of this latter problem as a modifiable risk factor because they believed that cleaning products thoroughly will wash off the harmful insecticides used on products.

With regard to non-modifiable risk factors and causes, the most commonly mentioned causes were environmental causes such as polluted drinking water, chemical toxins from the mine wells, lead poisoning from previous and current industrial companies in the region, and chemical waste dumped in adjacent rivers by industrial companies. Many participants had a common belief that those governmental agencies in charge were not doing their job in protecting people from the environmental causes and risk factors of CRC in the Appalachian region. One participant thought that the FDA officials "do not seem to be doing anything" because, as he believed, harmful types of food are still being sold in the market in "massive quantities." Family history of CRC was mentioned by many participants as a non-modifiable risk factor. Many participants expressed some thoughts of powerlessness with regard to the prevention of the 
disease. They thought that causes were either unknown, or as common and widespread as radio waves, free radicals, cell phones, and microwaves that no one can avoid.

(3) Timeline. It was notable that none of the participants thought of the CRC disease course as a cyclical disease. Participants thought of CRC as either chronic disease that stays in the body until death or acutely appearing in a life-threatening way that requires immediate medical attention. Participants were divided almost equally into these two views. Some participants thought of CRC as a fast growing disease that required immediate treatment. They thought that it appeared suddenly in a fast growing form, even when following screening guidelines (i.e., interim CRC). Many participants thought when treated, CRC is cured and patients survive the disease. They believed that the disease appears as an acute condition that grows quickly. One participant had an attitude of disengagement by indicating his preference not to be informed that he had CRC if he gets diagnosed with it. He thought that worrying about the disease will worsen his prognosis and result in more immediate death due to excessive worry.

Some participants thought of CRC as a chronic and slow growing disease that stays in the body for a long time until it causes death. For example, one participant commented: "I would rather die of a heart attack immediately than go through some long and very painful debilitating treatment." This participant was expressing how much suffering he perceived to be associated with CRC.

(4) Consequences. Many participants showed positive views with regard to the consequences of $\mathrm{CRC}$ by believing that $\mathrm{CRC}$ is curable. For example, one commented: "I am sure that it is such a slow growing cancer and you can cure anybody unless they catch it in last stages." Other participants showed a negative view about what happens to those who get CRC. 
The two major themes in these negative views were death and suffering. Regarding the first theme, most participants believed that death might be a consequence if the disease was not treated. However, participants differed in what leads to death. Some participants had a fatalistic view about $\mathrm{CRC}$, believing that being diagnosed with the disease will ultimately result in death. Others believed that death can be a consequence when cancer is diagnosed too late (i.e., in late incurable stages), or because of not following screening guidelines.

The suffering mentioned as consequences of CRC was of three types: physical, psychological, and financial. Physical suffering was in the form of pain caused by the disease, fatigue and deterioration of health caused by chemotherapy treatment, and surgery. However, most participants thought that all consequences could be minimized by early diagnosis, indicating the importance of following CRC screening guidelines. Psychological consequences included lowered self-confidence caused by the perceived need to use crutches, poor perceived health status, fear of threatening one's sexual functioning, and embarrassment of both having the disease and managing it, such as wearing the colostomy bag that collects the stool after having one's colon removed. Financial suffering would be the result of debt incurred due to treatment. For example, one participant said that he did not want to seek health care because he did not want to get poorer: "If you do not have the money, they will just come and take everything you own once you show up with that medical problem."

(5) Control/Cure. Issues of control and cure involve both perceptions of prevention and curability. 
Preventability and Control of Colorectal Cancer. Participants differed in whether CRC is preventable. Three views arose from responses: (1) prevention is possible, (2) prevention is impossible, and (3) prevention is possible, but difficult.

Prevention is Possible. The majority of participants believed that CRC was preventable. The main theme about preventability of CRC pertained to the role of a healthy lifestyle on health and CRC prevention. The influence of a healthy diet was the most discussed sub-theme. Almost all participants believed that diet was critical, both locally (by having good types of food going through the gastrointestinal tract (GIT)) and systemically (by consuming nutritional food that strengthens the body and helps it defend itself). Perceived good types of food included vegetables (especially home-grown vegetables), fruits, greens, salad, steamed loose leaf, beans, fish, grains, berries especially açai berry, baked chicken or turkey breast without skin or fat, and high fiber diet. One participant believed that balanced eating was the key. He thought that even healthy types of food should be eaten in moderation. Another participant thought that good types of food for athletes include beef, ice cream, cake, and coffee, a view that may not conform to specialists' recommendations (American Gastroenterological Association, 2013a). Perceived bad types of food mentioned by participants included meat, fat, deep fried food, pizza, soft food, fast food, hamburgers, salt, sugar, and alcohol.

With regard to other lifestyle behaviors, participants believed that regular exercise and quitting smoking helped to prevent CRC. Adhering to the screening guidelines and following physicians' recommendations were also recognized as practices to prevent CRC.

Prevention is Impossible. Many participants expressed the thought of perceived inability to avoid CRC. Some participants thought that there was a countless number of causes of CRC 
and/or too much ambiguity about causes and physiological mechanisms of the disease process, which makes prevention impossible. One commented:

We have literally millions of rays going through, radio waves, colors ... God knows how many other millions of things do that [cause CRC] ... We can only just look at the big picture. We are not able to really see each type of environmental thing that happens to us.

Prevention is Possible, but Difficult. Some participants thought that following health care professionals' recommendations, being free from CRC risk factors, and/or eating healthy were not necessarily sufficient to protect against CRC. Likewise, it was believed that some of those who assumed a healthy lifestyle, had no risk factors, and ate healthy meals develop the disease. Participants reported that environmental causes of cancer in the Appalachian region make it more difficult for the health care sector to control the spread of many types of cancers among Appalachians. Participants also reported other factors that made it difficult to control CRC, such as having family history of cancer, lack of healthy eating habits in the culture of the family or household, and low socioeconomic status in comparison with the rest of the nation. Such factors were believed to make Appalachians less attentive to preventive medicine.

Curability of Colorectal Cancer. The majority of participants thought that (1) CRC was curable, whereas some participants believed that (2) it was incurable.

Colorectal Cancer is Curable. Many participants thought that CRC was curable. Most of these participants believed that early diagnosis was an important factor in determining prognosis and curability, as curability and survival chances were believed to diminish depending on how late the disease was diagnosed. Participants had variable views on how the disease can be 
treated or cured. Treatment options mentioned by participants included chemotherapy, radiation, shots, consuming healthy diet, consuming anti-oxidants, and surgery. Surgery was the most commonly mentioned treatment option. One participant mentioned "cobalt" as a treatment option of cancer where it seemed he referred to cobalt-60, which is a type of radiation therapy used in treating certain types of cancer such as brain tumors.

One participant believed that there was no need for chemotherapy and other treatment options because he thought surgery was the gold standard for treating the disease. Other participants thought that surgery was not the best option in treating the disease. One participant had an apprehensive feeling toward surgeries, by stating: "I think about how if I did this surgery, I will not be able to be a man anymore. I guess that is a dumb thing to say but you know I hate to lose that." This participant thought that surgical procedures associated with CRC treatment would threaten his sexual functioning, perhaps indicating confusion about the surgery itself. It was notable that when asked about the curability of CRC, some participants mentioned colostomy and wearing "the bag" as they thought that all types of CRC surgeries are associated with this consequence.

Many participants did not specify any treatment options and left it to the discretion of health care professionals to decide what the best treatment might be. A few participants believed that curing CRC was out of patients' personal control and depended on mere luck. For example, one participant noted: "It is not something you can get away from, and if you do, you are very lucky." This participant thought that personal behavior did not matter in curability, but luckiness did. Another participant mentioned that some of his acquaintances believed that the disease may disappear by itself or might be cured through prayer, but the participant himself did not believe 
so. In summary, despite some misunderstandings of how the disease might be managed, most participants were aware that early diagnosis was imperative toward more successful treatment.

Colorectal Cancer is Incurable. Some participants believed that when physicians address CRC management, they merely try to improve the quality of life and delay death. One participant thought that the disease was not curable due to the natural presence of bacteria in the colon, believing that bacteria caused incurable infections when cancer presents. Some thought that health care professionals in the U.S. are not serious in finding a cure for the disease. According to one of the participants, if U.S. health professionals were serious in finding a cure they would have found one as their German counterparts did. He went on to state: "We should take a little bit of time and work with them and let them give us their knowledge." This participant expressed some religious thoughts in regard to curing the disease. He believed that since there was no cure for colorectal disease in the U.S., patients depend on God's mercy during the course of the disease.

After comparing the responses of screeners and non-screeners, it was clear that most screeners thought of CRC as curable if caught in time. However, non-screeners were more likely to express both positions; some thought it was easily cured, whereas others thought there was no cure at all. This indicates oversimplification of the disease among non-screeners, which may render them less attentive to being adherent to CRC screening guidelines.

\section{Representation of Emotion}

Feelings about Colorectal Cancer. Two types of feelings were extracted from the interviews about feelings related to CRC: (1) fear, discomfort, and physical harm, and (2) disengagement. 
Fear, Discomfort, and Physical Harm. All participants believed that CRC was one of the most devastating diseases that anyone may get. Many participants labeled CRC as being "terrible" or "horrible" health condition, or saw it as a "fearful," "scary," or "serious" condition. Many participants thought they would go through much physical harm if they were diagnosed with CRC by believing that CRC is "cruel," "violent," or associated with pain. One of the participants was very worried about his chances of getting CRC due to seeing some of his acquaintances die from it. This worry had been translated to many behavioral changes such as seeking more information, trying to avoid the perceived causes, and more communication with health care providers.

Disengagement. A few participants showed an attitude of disengagement toward CRC as they were assuming a day-to-day life. They thought that they should not worry about their future chances of getting the disease, but they would worry only if they were diagnosed with it. The attitude of disengagement was more salient for participants who reported limited access to health care. They may have believed that not worrying about the disease was the only choice they had. One participant showed an attitude of disengagement to any possible CRC diagnosis in the future, by saying: "I don't want the worry. Let it [diagnosis of CRC] go." He believed that he should not worry even if he was diagnosed with CRC.

Feelings about Colorectal Cancer Screening. Feelings about the screening of CRC were categorized into two groups: (1) difficult/unpleasant feelings, and (2) accepting feelings. The majority of feelings mentioned by participants were in the first category. 
Difficult/Unpleasant Feelings. Most participants had concerned feelings about the screening process itself. Four themes were extracted: (1) embarrassment, (2) hurt/discomfort, (3) perceived inappropriateness of screening tests, and (4) fear and worry.

Embarrassment. Many participants described the screening for CRC as a socially inconvenient procedure and believed that embarrassment was a barrier to adhering to the screening guidelines. A few participants indicated feeling discomfort of having some areas of their body exposed. One participant described how the rural area where he lives in is part of the "Bible-belt" that is inhabited by "conservative" people. These people, as the participant thought, are more likely to show embarrassment, and consequently are less likely to adhere to the screening guidelines.

Hurt/Discomfort. A hurt/discomfort theme noticed was of two types: hurt/discomfort associated with the screening procedures and discomfort associated with the preparation for the screening. Participants labeled screening procedures as "horrible," “a hassle," or "rough," indicating a feeling of hurt or inconvenience. Although some acknowledged the importance of screening, they still showed their negative feelings towards it. One participant explained his feeling towards CRC screening by describing it as "a necessary evil." A few participants thought that the preparation can be as bad as screening itself. Drinking the preparation liquid to empty the gastrointestinal tract was also mentioned as a point of discomfort before the screening.

Perceived Inappropriateness of Screening Test. A few participants had negative views about the screening tests. They believed that CRC screening tests were not important because test results either "turn out for the best" (results show no disease exists) or physicians would not be able to do much for cancer patients. Those who thought screening tests were not effective 
tended to have poor perceived quality of life and more helpless feelings in which they believed their poor health was caused by external factors, not due to their own behavior. Another way of believing that screening tests were not helpful was the belief that it did not provide any more information than what visual observation can do. Some participants argued that more research was needed on CRC screening in order to come up with new screening tests that were not expensive, not scary, not invasive, and not embarrassing. One patient thought that screening was not cost-effective unless there was something clearly wrong, by stating: "If you did not have any problems, then you lose your money when you screen. The screening did not worth the money unless you are sure there is something wrong."

One participant showed a powerless feeling when conducting the screening associated with the need to expose one's body in front of physicians. Although he did not mention prostate exam per se when he was probed about CRC screening, it was notable that he mentioned exposing the body during a prostate exam, perhaps indicating the link some participants made between the inconvenience associated with screening for both diseases:

It is an uncomfortable thing, but like I say, I do not care if he [the examiner] sticks his finger up ... it is better than cancer. That is the way I look at it. I figure you know, you are good before a doctor, when you are laying on the table, you are at his mercy.

The feeling of powerlessness due to financial barriers appeared in some responses. Many participants indicated that they wanted to screen, but there was nothing they could do as they neither had money nor health insurance to cover screening expenses. 
Fear and Worry. A few participants expressed their fear from the having the screening tests. Many thought that some people do not screen because they are afraid of the screening procedures. For example, one participant stated: "Some of the tests are more scarier than the disease," a participant indicating his feeling about some of the screening tests.

Worrying about the screening results made some patients feel uncomfortable. Many participants indicated being concerned when thinking about CRC screening as they expressed the fear that screening would reveal health problems that make them suffer later.

Accepting Feelings. Many participants had positive views about the screening tests by indicating that $\mathrm{CRC}$ screening tests are not associated with pain, which made them feel that the tests were patient-friendly. Some described how beneficial such tests were and how helpful they were in keeping people healthy. One participant thought that people were changing positively and expressing less embarrassment and more openness to such beneficial tests over time. One participant made a comparison between $\mathrm{CRC}$ screening tests and tests that women do at the gynecologist. He said that he needed to "toughen up" and show more courage for such tests that helped him live longer and healthier.

Most participants acknowledged the importance of frequent screening in protecting against the disease even when no symptoms were present. They believed that life could be saved and the disease could be prevented through such tests. Further, they recognized that the presence of some barriers should not be an obstacle to performing the screening because the sought benefits outweighed the negative thoughts and feelings. The majority of participants thought that it was much worse to get cancer or die due to advanced cancer than to get embarrassed or temporarily feel uncomfortable. 


\section{Discussion and Conclusion}

It was notable that powerlessness was the most common negative theme indicated by participants. This was a result of either not having the means to obtain screening (i.e., access to health care) or holding a fatalistic view by believing that CRC was neither curable nor preventable. This notion of perceived incapability to control CRC affected the way some participants behaved in regard to the health threat associated with it. This finding overlaps with previous research examining the effect of perceived behavioral control and locus of control on general behavior (Ajzen, 2002).

What may aggravate the issue of powerlessness is the widespread unfamiliarity with CRC symptoms among some participants through either not being able to identify the symptoms or not being able to distinguish between symptoms of CRC and symptoms of other diseases.

Additionally, awareness campaigns are needed to address the need to screen for colorectal cancer through following the screening guidelines even when no related symptoms are experienced. Such findings may reflect the need for awareness campaigns across the Appalachian region in order to address people's needs in obtaining better health care. Unfamiliarity with the screening guidelines was also a factor that led to sub-optimal health behavior, a factor that was observed in previous studies with regard to rural Appalachian population (Bardach et al., 2011; Tessaro et al., 2006).

Financial barriers that led to not visiting physicians regularly were some of the factors that led to reduced efforts to seek preventive care among study participants. Previous studies investigating CRC screening campaigns in the Appalachian region have reported comparable barriers (Lengerich et al., 2006; Paskett et al., 2013). 
It was also noteworthy that not screening for CRC was sometimes a result of perceiving unreasonable barriers that participants thought were real obstacles to screening. Barriers to CRC screening in the Appalachian population included (1) fear (Kelly et al., 2007; Tessaro et al., 2006), (2) embarrassment (Kelly et al., 2007; Coughlin et al., 2006), (3) not trusting health care professionals (Hatcher, Dignan, \& Schoenberg, 2011), (4) not trusting researchers, and (5) the perceived incapability of governmental insurance programs to provide the care that was desired. Examples of the unawareness that some participants had about the disease itself and the true treatment cost were evident in this sample. While this perspective showed sophisticated reasoning, it lacked knowledge that lack of screening may result in higher costs due to failure to catch the disease at the polyp stage or the fact that delayed treatment results in more aggressive management strategies.

Thoughts extracted from the interviews represented a wide spectrum of notions related to CRC-associated behavior. Some of these thoughts have not been reported in the literature and found by this study to be specific to the Appalachian population. For example, the mentality of letting symptoms "take care of themselves" or asking "old folks" instead of seeking care from health professionals may worsen the problem of delayed health care. Additionally, thinking about CRC as a stigma was the reason some participants believed that it was socially inacceptable to talk about CRC-related issues, which may aggravate the problem of widespread unawareness about CRC symptoms and screening guidelines.

Further, it was noteworthy that some participants thought that vegetables bought from the market may harm the body rather than benefit it. They believed that chemicals, such as fertilizers, caused CRC. Therefore, they preferred eating home-grown vegetables or not eating market vegetables at all over consuming vegetables bought from the market. This belief may 
exacerbate the problem of widespread food insecurity documented in rural Appalachia (Pheley, Holben, Graham, \& Simpson, 2002). As a result, thinking about a healthy type of food in such a negative way may partially explain not following the recommended dietary guidelines. Such difficulties are more challenging in the region considering the widespread poverty (Duncan, 1992) and low rates of college graduation and advanced degree attainment (Bollinger, Ziliak, \& Troske, 2011) among Appalachian residents.

Uncertainty was also noticed in the study sample as some participants gave contradicting answers to many questions. For example, one participant thought that $\mathrm{CRC}$ was a relatively fast growing disease that grew faster than prostate cancer, but slower than breast cancer. Then, the same participant said, while discussing a different topic, that $\mathrm{CRC}$ is a relatively slow growing cancer in a way that patients, as the participant thought, died from old age rather than CRC. This may indicate the lack of knowledge about the disease process in some people's minds, and the fact that some people do not have a concrete understanding of the timeline for CRC. Again, this lack of knowledge may partially explain the poor health behavior among the studied population and confirms the need for educational interventions in the Appalachian region (Tessaro et al., 2006).

Factors associated with CRC worry varied among participants. Some participants reported that seeing others dying from the disease would make them worry about it. Other participants indicated that having related symptoms such as bleeding or pain was the trigger that made them worried. A third perspective of what makes the person worried is talking about the disease, as two of the participants became worried when chances of CRC were discussed during the interview itself after being not worried about the disease or thinking about it prior to participating in the study. This qualitative research project enabled us to clarify some of the 
factors that affected the magnitude of CRC worry. Previous literature has only shown educational attainment (Collins et al., 2000) and perceived risk (Zajac et al., 2006) were factors that affected worry.

The most common cue associated with CRC for seeking health care reported by interviewees was the presence of symptoms that suggested colon or rectal problems (i.e., a health threat). However, some participants thought that there was no need to see a physician when first experiencing symptoms. They thought that only persistent symptoms or symptoms that negatively impacted the functionality of the body warranted seeing a physician. Many participants thought that temporary symptoms were not worth making an appointment to see a physician, which is an example of appraisal delay that leads to worse prognosis as indicated in previous research (Andersen et al., 1995). This finding was consistent with what the literature suggests about the effect of symptom severity on health care seeking behavior especially regarding gastrointestinal diseases (Koloski, Talley, \& Boyce, 2001).

It is important to mention that screening for colorectal cancer should be conducted regularly as prescribed by the U.S. preventive Services Task Force guidelines (2008). These guidelines should be followed taking into account the absence of any related symptoms. However, diagnostic screening is conducted as a result of experiencing symptoms as patients seek health care in order to address the worry they have resulted from such symptoms. It is noteworthy that that many participants incorrectly referred to CRC screening as diagnostic screening. Although participants had positive views about the effectiveness of CRC screening tests, some believed that screening is required only when symptoms are experienced. 
Future Considerations. The sample did not include non-Appalachian residents. Therefore, comparison between Appalachian and non-Appalachian residents could not be made in this study. Future research may include both Appalachian and non-Appalachian residents. Asking the same questions to Appalachians and non-Appalachians in the same study would enable pointing out the differences between both of them after controlling for other factors.

Most participants in this study $(64.3 \%)$ perceived their health as Fair/Poor. Considering the strong association between poor perceived health and the risk of mortality (DeSalvo, Bloser, Reynolds, He, \& Muntner, 2006; Franks, Gold, \& Fiscella, 2003; Kaplan \& Camacho, 1983), it is clear that more attention should be given to the population of Appalachia in order to address health care disparities they face, especially in preventive care. Many of the mentioned barriers for CRC screening may be resolved by improving patient-physician communication in order to increase the utilization of screening programs. Such a modification would likely have positive benefits for diseases outcomes other than CRC as well.

Additionally, more effort needs to be made in order to improve health care access in the Appalachian region (e.g., making screening tests more financially affordable). A special consideration should be given to people from low socioeconomic classes such as those who live in the Appalachian region. Hopefully, increasing access to health care planned by the Patient Protection and Affordable Care Act (2010) will help fix such problems that are prevalent in the Appalachian region. Changes associated with this law are expected to have significant impact on the health of people from low socioeconomic status. This greatly pertains to the population of rural Appalachia, considering that more than half of the participants $(53.3 \%)$ in the study sample had an annual household income of $\leq \$ 10,000$. 


\section{Manuscript \# 2}

\section{Introduction}

Considering the role of affective representation (i.e., feelings and emotions about CRC) in generating behavior aiming to offset the health threat of diseases (i.e., the threat of CRC) (Leventhal, Brisette, \& Leventhal, 2003a), it is necessary to examine the magnitude of affective representation (i.e., CRC worry) in a sample of Appalachian inhabitants in order to understand the behavior of this population regarding engagement in CRC screening adherence. From a theoretical point of view and according to the Self-regulation Model, worry may act as a cue to CRC screening because anxious individuals would be more likely to seek health care in order to address this affective representation of the health threat caused by CRC. Further, worry has been cited as a facilitator that may predict engagement in preventive care (Diefenbach \& Leventhal, 1996; Leventhal, 1970; Leventhal \& Cameron, 1987).

Additionally, to better understand the magnitude of CRC worry people have, factors that are associated with it need to be identified. Previous research has produced only limited information about predictors of cancer worry, and even less information is available in the literature about the predictors of CRC worry. This quantitative study on a sample of Appalachian women examines the modifiable and non-modifiable factors that significantly are associated with the magnitude of CRC worry within rural Appalachian population. The results of this manuscript may help in designing future interventions that may employ altering the construct of CRC worry in generating healthy behaviors such as adhering to CRC screening guidelines.

\section{Hypotheses}


Four hypotheses were proposed in this research study. Based on the positive association between perceived risk for CRC and CRC worry within the general population (Collins et al., 2000; Hay et al., 2006; Vernon et al., 2001; Zajac et al., 2006), we hypothesized that (1) Appalachian residents who perceived their CRC risk (both comparative risk and absolute risk) to be higher were more likely to express CRC worry than those who perceived lower risk.

The negative impact of fatalism on health behavior has been reported in Appalachia (Behringer \& Krishnan, 2011; Coyne, Demian-Popescu, \& Friend, 2006a; Lewis \& Billings, 1997; Royse \& Dignan, 2001; Royse \& Dignan, 2001; Shell \& Tudiver, 2004; Vanderpool \& Huang, 2010). Since people who score higher in fatalism typically perceive cancer as equivalent to death (Powe \& Finnie, 2003), we expected that they would be more likely to worry about the disease. Therefore, we hypothesized that (2) people who scored higher in fatalism were more likely to express CRC worry than those who scored lower in 44atalism.

Previous research has reported that religion is an important factor that plays a significant role in Appalachian residents' behavior (Photiadis, 1977), especially behavior pertaining to cancer care (Behringer \& Krishnan, 2011). Thus, we expect that religious commitment helps patients to cope with stressful conditions and makes them more likely to have a stable and healthy life, with less fear and anxiety about the future. Based on that, we hypothesized that (3) religious commitment was negatively related to cancer worry, such that people who scored higher in religious commitment scale were less likely to have CRC worry than those who scored lower in religious commitment.

Based on previous research investigating the impact of health care access and affordability on psychological state (Keeler et al., 1987), we expected that people who live in 
isolated or rural localities, like many Appalachians, may express more cancer worry because of limited access to health care due to economic difficulties, or geographic isolation. Based upon this position, we hypothesized that (4) people who have limited access to health care were more likely to express CRC worry than those with greater access to care.

\section{Participants}

All participants in this study were residents in the Ohio Appalachian region. Participants were recruited by reviewing medical records to determine eligibility (a HIPAA waiver was requested in order to contact these participants). Patients were then mailed a postcard and a description of the research project and asked to return the postcard if they would like to opt-out and choose not to participate in the study. One hundred thirty seven participants were included in this study. All of them were females and 18 years of age or older at the time of data collection. Pregnant women were excluded from the analysis. Included participants had no personal history of CRC.

\section{Procedures}

This research design was based on a cross-sectional study employing survey methodology to collect information from Appalachian women. Institutional Review Board (IRB) approval was obtained. Medical records were randomly selected from a local health department and reviewed for eligibility. Eligible participants were mailed structured surveys (Appendix 3) and had the option to have the questionnaire conducted by a telephone interview if they had difficulty reading. Participants were asked to sign informed consent forms before completing the questionnaires. A second mailed packet was sent 2-3 weeks later for participants who did not respond to the first request. 


\section{Measures}

The following measures were employed: demographic data [county of residence: to determine rural residence (United States Department of Agriculture, 2013) and confirm Appalachian residence (Appalachian Regional Commission, 2013)], parents' residence in Appalachia, poverty, age, gender, and education.

Fatalism. Fatalism was evaluated using the Powe Fatalism Index (PFI) (Powe, 1995). This measure encompasses four attributes of fatalism: fear, pessimism, predetermination, and inevitability of death. This index is composed of 15 items, with yes/no answers. The Cronbach's Alpha for PFI instrument was reported to be 0.87 , indicating acceptable internal consistency of the measure (Powe, 1995).

Religiousness. Religious commitment was assessed using the short-form of the Religious Commitment Inventory (Worthington et al., 2003). The inventory contains 10-items using a 5point Likert response format (Not at all, Somewhat, Moderately, Mostly, Totally). The coefficient alpha for this scale was previously reported as 0.93 , indicating good internal consistency reliability (Worthington et al., 2003).

General Mood. General mood was assessed using the short-form of the Profile of Mood States (POMS) (Lebo \& Nesselroade, 1978; McNair, Lorr, \& Droppleman, 1971; Shacham, 1983). This measure contains 30-items using a 5-point Likert response format (Not at all, A little bit, Moderately, Quite a bit, Very much). This measure encompasses six attributes of general mood: tension, anger, depression, confusion, vigor, and fatigue. The internal consistency for the short form of the POMS was reported as 0.87 for healthy (cancer free) subjects and up to 0.92 for other subsamples of cancer patients (Curran, Andrykowski, \& Studts, 1995). 
Cancer Worry. Cancer worry was assessed with a modified version of the Cancer Worry Scale adapted to CRC (Lerman, Kash, \& Stefanek, 1994). This measure contains 4-items using a 4-point Likert response format (Not at all, Sometimes, Often, A lot). The reported alpha coefficient for this scale was 0.76 (Lerman et al., 1991).

\section{Power Analysis}

Power analysis was conducted in order to determine the appropriate sample size required for detecting a medium effect size, based upon the fact that previous studies have found effect sizes of this magnitude. The statistical software program used to conduct the analysis is PASS ${ }^{\circ}$. Taking into account a defined number of participants $(n=137)$, and the medium effect size expected $(\mathrm{P} 0=0.4$ and $\mathrm{P} 1=0.2)$ based upon prior work using the Religious Commitment Index variable, power was determined to be 0.90533 for an $\alpha$ level of 0.05 . According to this analysis, the study included a sufficient sample size to detect significant differences.

\section{Plan of Analysis}

Version 21 of SPSS $®$ program was utilized in conducting the analyses. Descriptive statistics were conducted to examine the frequencies, means, and standard deviation of item responses and to check for normality of distributions of study variables. These assumptions were examined in order to determine the appropriateness of different variables in conducting the planned statistical tests. The distributions of several continuous variables were found to be skewed (i.e., not normally distributed). Consequently, square root transformations were conducted in order to correct the distributions of those variables. These variables were: (a) the Religious Commitment Index Interpersonal Sub-scale, (b) the Profile of Mood States: Tense, Anger, Depression, and Confusion Sub-scales, and (c) the Fatalism summed scale. 
Cancer Worry was dichotomized using the Cancer Worry Scale adapted to CRC (Lerman et al., 1994); participants were divided into two groups: the "No Worry" group (for those who reported "not at all" on all 4 items of this scale) and the "Worry" group (for those who reported some worry). Due to few numbers of respondents being categorized into many cells across different variables (where some responses had less than 5 participants), responses to many categorical variables were collapsed into fewer responses in order to more uniformly distribute participants across different categories. Responses to Race and Ethnicity questions, for example, were collapsed into one variable with 2 responses: (1) Non-Hispanic White or (2) other Races, mixed Races, or Hispanic Ethnicity. Perceived risk was assessed by one question that asked participant to rate their health in the past 4 weeks. Responses were collapsed into 2 responses: (1) excellent, very good, or good or (2) fair, poor, or very poor.

Absolute perceived risk was assessed by three items. The first item asked the participants to report a percentage that corresponds to likely they are to get CRC (0\%-100\%). The second item asked the participant about whether they thought that they might get colon cancer (Yes, No). The third question asked participants about their likelihood of having CRC cancer (not at all, somewhat likely, very likely or definitely). Comparative perceived risk was assessed by two questions. The first question asked about the perceived vulnerability in comparison with other women. Responses were: (1) higher, (2) same, and (3) lower. The second question asked about likelihood of getting colon cancer in lifetime in comparison with other women at same age. Reponses to this question were collapsed into 3 categories: (1) below average or much below average, (2) same, (3) above average or much above average.

Bivariate analyses were examined to check the association of demographic, psychological, and cultural variables with the outcome variable. These associations were 
examined either through conducting Chi-Square analyses to check the association of categorical variables with the outcome variable or through independent sample t-test analyses in order to examine the association between continuous variables and the outcome variable. Variables that showed a $p$-value of $\leq 0.1$ in bivariate analyses (Chi-Square and t-test) were entered in the final Binary Logistic Regression model as predictor variables with the newly created dichotomous variable ("No Worry" and "Worry") as the outcome variable. The use of a $p$-value of $\leq 0.1$ as a cut point was for the purpose of eliminating all continuous and categorical variables that were unlikely to be significant in the final binary logistic model. It was assumed that those variables that had a $p$-value of $\leq 0.1$ would be likely to show significance, and hence, included in the final model. Binary Logistic Regression was conducted using the backward stepwise method. Independent variables with p-values $>0.05$ were eliminated sequentially until we arrived at a model with all independent variables having $p$-values of $\leq 0.05$. The use of backward stepwise method was to enable SPSS ${ }^{\circledR}$ program to select predictors based on lowest $p$-values (i.e., strongest predictors statistically). If predictors of CRC worry were studied in the Appalachian region prior to this paper, other methods (e.g., hierarchical method) may have been warranted in order to test a specific theory, for instance, by determining the order of variables entry to model due to previously known importance of different predictors. However, due to the limited prior research examining these variables, the backward stepwise method was selected.

\section{Results}

Out of the 137 participants interviewed, one was excluded because county of residence was located outside the Appalachian region. Regarding the dependent variable, $55 \%$ did not have any worry at all whereas $45 \%$ expressed some worry. The mean for responses to Cancer Worry Scale ranged from 1 to 4 with a mean value of 1.40. Responses to fatalism summed scale ranged 
from 1 to 15 with a mean value of 4.62. Responses to Religious Commitment Intrapersonal Subscale ranged from 5 to 25 with a mean value of 12.21. Responses to Religious Commitment Interpersonal Sub-scale ranged from 5 to 25 with a mean value of 10.57 . With regard to income level and economic difficulties, data from the sample were compared with the poverty level in the United States was reported by United States Census Bureau of 13.2\% in 2008 (DeNavasWalt, Proctor, \& Smith, 2009). It was found that $66 \%$ of participants in this study were under the poverty line $(t(136)=13.01, p<0.001)$, which suggests that financial challenges confront rural areas of Appalachia. Participants' age ranged from 19 to 68 years old, with a mean of 40.3. The age range was fairly distributed among different ages categories. Those from $19-29$ years old category composed $27 \%$ of the study sample. Those from 30 - 39 years old category composed $23 \%$ of the study sample. Those from $40-49$ years old category composed $23 \%$ of the study sample. Finally, those who were at least 50 years old composed $27 \%$ of the study sample.

Chi-Square tests were conducted between the outcome dichotomous variable and categorical independent variables (Table 1). With regard to variables that showed a p-value of $\leq$ 0.1, it was found that those who were not worried about CRC were more likely to (1) believe that they have lower risk for getting CRC than other women, (2) have a GED or have only high school education (as opposed to those who graduated from colleges with degrees or had at least some higher education from colleges, technical schools, or trade schools), (3) be employed (as opposed to being unemployed, retired, or disabled), (4) have uncertainty about their access to a gastroenterologist as opposed to those who thought the access was "easy," (5) perceive CRC to be less serious or deadly (as opposed to those who thought CRC as very serious or deadly), (6) think they would be among those who will not get CRC, (7) perceive their likelihood of getting $\mathrm{CRC}$ in their lifetime as below average or much below the average for other women, (8) believe 
that they are unlikely to get cancer in the future, and (9) never attend religious services as compared to those who attend religious services less than once a week. Each of these variables was entered in the final binary logistic model.

Regarding the continuous variables, t-tests were conducted between these variables and the outcome dichotomous variable (Table 2). With regard to variables that showed a $p$-value of $\leq$ 0.1, it was found that those who were not worried about CRC were more likely to (1) perceive lower chances of getting CRC among the general population, (2) perceived lower personal chances of getting CRC before the age of 70, and (3) score lower in POMS tense, confusion, and fatigue sub-scales. The use of a $p$-value of $\leq 0.1$ cut point was to reduce the number of variables entered in the final model, as only variables that had $p$-values of $\leq 0.1$ were entered in the final binary logistic model.

After variables that showed significance $(p<0.1)$ in the chi-square and t-test analyses $(\mathrm{a}$ total of 15 variables) were entered in the final model of the binary logistic regression analysis using the backward stepwise method, 10 independent variables with p-values $>0.05$ were sequentially eliminated through 10 steps until the model had only significant predictor variables that had p-values $\leq 0.05$ in step 11 (Table 3 ). This sequence eliminated 10 variables through 10 steps. Eliminated variables were respectively: (1) perceived deadliness of CRC, (2) confusion subscale of the POMS instrument, (3) perceived vulnerability (odds of getting cancer again in comparison to others: higher, same, lower), (4) perceived personal vulnerability (chance in \%) of getting CRC before the age of 70, (5) lifetime likelihood of getting CRC in comparison with other women same age, (6) occupational status, (7) fatigue subscale of the POMS instrument, (8) perceived seriousness of CRC, (9) chances be among those who get CRC or who do not get 
$\mathrm{CRC}$, and (10) frequency of attending services. Variables that remained in the equation were examined to determine beta values and confidence intervals (Table 4).

Through examining the $\operatorname{Exp}(\mathrm{B})$ column in table (4) below, we found that those who had graduated with a college degree or had at least some higher education were more than 9 times as likely to be worried as those who had GED or maximum of $12^{\text {th }}$ grade $(\operatorname{Exp}(B)$ value in table (4) = 9.21). The overall Access to Gastroenterologist variable was significant. However, those who had uncertainty about the access they had to a Gastroenterologist (who answered: Do not know or neither easy nor difficult) were $89 \%$ less likely to be worried than those who thought they had easy access to a Gastroenterologist $(\operatorname{Exp}(B)$ value in table $(4)=0.11)$. The comparison between those who answered difficult and those who answered easy was not significant. As compared to those who thought they were not likely to get CRC, those who thought that they were likely to get CRC were more than 8 times as likely to be worried $(\operatorname{Exp}(B)$ value in table $(4)=8.35)$. Additionally, for every one percent increase in perceived vulnerability scale to CRC, there was a $3.4 \%$ more likelihood for participants to be worried about $\mathrm{CRC}(\operatorname{Exp}(\mathrm{B})$ value in table $(4)=$ 1.034). Finally, for every one unit increase in the tense subscale of the POMS instrument, participants were more than 15 times more likely to be worried about $C R C(\operatorname{Exp}(B)$ value in table $(4)=15.78)$. Independent variables were examined for multicollinearity through conducting correlation analysis. Some significant correlations were noticed, but no Pearson correlation values of $\geq 0.3$ were found, which indicates not having any significant multicollinearity problems between independent variables (table 5).

\section{Discussion and Conclusion}


The purpose of this manuscript was to investigate the factors that associated with CRC worry. As we learn of more about of the predictors of CRC worry, researchers will be more able to improve people's health behavior toward screening adherence through health behavior interventions. Theoretically, the affective representation of the health threat may influence engagement in action plans that people do in order to avoid such health threats (i.e., diseases) (Leventhal, Brisette, \& Leventhal, 2003a). Previous literature suggested that worry may predict adherence to CRC screening tests (Myers et al., 1994). Therefore, researchers in the future may intervene by modifying the magnitude of worry people have in order to change improve health behavior.

Although 15 categorical and continuous variables were significantly associated with the outcome variable when individually examined through Chi-square and t-test analyses, only 5 of them were found significantly associated with the outcome variable in the final model of the binary logistic regression. The association of education with CRC worry in this study was consistent with previous literature as more educated individuals expressed more worry regarding CRC than less educated individuals (Collins et al., 2000). This may suggest a higher magnitude of problem-solving skills that educated people use, considering that the Self-regulation Model assumes that people are active problem-solvers. Further, this result may indicate that more educated individuals are more likely to think of CRC as a health threat and consequently more likely to seek health care. It is noteworthy that worry may act as a cue to screening to cancer because it is a component of the affective representation people may perceive about cancer (Hay, McCaul et al., 2006).

The association of absolute perceived risk for CRC with worry associated with $\mathrm{CRC}$ was consistent with previous studies (Zajac et al., 2006). Those who thought they were more 
susceptible to CRC according to the Common Sense Model (e.g., due to the belief of having risk factors) were more likely to think of CRC as a greater health threat, and consequently, more likely to have a greater extent of worry about CRC in their affective representation of the disease. However, due to the cross-sectional nature of this manuscript, it would not be possible to expand on the relation between higher perceived risk and elevated CRC worry. Future research may explore the causal relationship between these two constructs through longitudinal studied for instance.

The finding that tense sub-scale of the POMS may act as a predictor of CRC worry was undocumented in the literature. Thus, those who expressed higher tension or anxiety in their general mood were more likely to show CRC worry. This association is, however, understandable considering that the construct of worry highly correlates with the feelings of anxiety and tension (Borkovec, Robinson, Pruzinsky, \& DePree, 1983). Future research may explore this association in order to see which items of this subscale (tense, on edge, uneasy, restless, nervous, anxious) were associated with CRC worry. Additionally, the finding that access to health care (i.e., access to Gastroenterologist in this study) acts as a predictor of CRC related worry was undocumented in previous research. It was notable that those who had uncertainty about their access to a Gastroenterologist had significantly lesser magnitude of worry than those who had easy access to it, whereas those who had difficult access were not different from those who had easy access. This may indicate that the confusion about whether seeing a Gastroenterologist is easily accessible might be a more contributing factor to the magnitude of CRC associated worry than not having an easy access at all. This may suggest the importance of self-system factors in determining the affective representation people may have about the disease. 
No prior studies have examined the factors predicting CRC worry in the Appalachian population as presented in this manuscript. Previous articles studied other populations or examined factors associated with worry or CRC worry individually (using $X^{2}$ or t-test) without incorporating such significant factors (in the bivariate analysis) together into a statistical model such as binary logistic regression.

\section{Limitations}

This study was part of a larger study investigating cervical cancer along with CRC cancer. Therefore, participants included were all females. This may limit the generalizability of results. More studies examining men's views in Appalachia and both genders' views in nationally representative studies might be conducted in the future. Further, considering that the minimum age of participants of this study was 18 , the results may be generalized to that age range, but not to those above 50 years old who are required to have CRC screening according to the U.S. Preventive Services Task Force guidelines (2008). Additionally, the sample for this study was only from the Appalachian region in the State of Ohio. Therefore, the results of this manuscript may be only generalized to that population.

Considering that fatalism was expected to correlate with CRC worry but was not associated with it in the bivariate analysis, future research may consider utilizing other instruments to measure fatalism at the Appalachian population. The scale used in this study was first developed to measure the magnitude of fatalism in African American populations, and indeed, it was validated to be used in that population. Therefore, it might not have been the optimum choice for our sample where the majority was of those who were of Caucasian race. A previous study has also noted the shortcomings of this scale in measuring fatalism where some 
researchers have noted that it may measure lack of confidence and knowledge about the treatment efficacy rather than fatalism (Abraido-Lanza et al., 2007). Other scales to assess perceived externality of factors influencing health or behavior may be utilized such as Health Locus of Control (Wallston, Wallston, Kaplan, \& Maides, 1976).

\section{Summary of Both Manuscripts}

Despite the advanced medical technology in cancer detection and treatment, nonadherence is unfortunately documented among some people such as Appalachians. In addition to the well-known limited access to health care services in some rural areas in Appalachia (Huttlinger, Schaller-Ayers, \& Lawson, 2004), people's unhealthy lifestyle may aggravate health problems and may lead to lower utilization of health care services. Moreover, it is a fact that health disparities in Appalachia make people prone to worse prognosis and contribute to elevated health care costs (Bolin, 1996) in states where poverty is more dominant than it is in other states (Duncan, 1992).

In order to address health care problems in rural Appalachian areas and identify the uniqueness of health behavior and beliefs among rural Appalachians, the Self-regulation Model was utilized to guide analysis in this research study. This research is composed of two manuscripts. The first manuscript utilizes qualitative data. The purpose of this manuscript was to investigate the cognitive representation (what the health threat was) and the affective representation (emotions and feelings associated with the health threat) related to $\mathrm{CRC}$, appraisal delay due to not seeking health care once required, and symptom identification and interpretation. The second manuscript utilizes quantitative data. The purpose of this manuscript is to examine CRC worry predictors in a sample of Appalachian women. Through studying the 
Appalachian population, these two manuscripts help to identify some features of health care attitudes and beliefs in this population that may affect the way people behave toward their health in Appalachia, specifically with regard to preventive care such as CRC screening.

Analyses on the sample of men revealed that lack of knowledge about preventive care combined with financial and cultural barriers were the most important factors that led to unhealthy behavior in the Appalachian population. Further, quantitative analyses on the sample of women showed that higher education, higher perceived risk to $\mathrm{CRC}$, tension/anxiety, and uncertainty about the access to health care specialists were significant predictors of CRC worry. It was apparent from the results of both studies that educational interventions and increasing access to health care may improve health care seeking behavior especially preventive care such as adhering to colorectal cancer screening guidelines.

With regard to factors that were associated with CRC worry, comparison between results of manuscript \# 1 and results of manuscript \# 2 revealed some important differences. Manuscript \# 1 (the qualitative research) helped in clarifying factors that triggered worry regarding CRC. These factors were seeing others being diagnosed with CRC or dying as a consequence of getting CRC, experiencing symptoms that suggest GI problems or colorectal-specific diseases, and talking about chances of getting CRC and discussing matters related to it. Whereas manuscript \# 1 showed the factors that initiated CRC worry, manuscript \# 2 (the quantitative research) helped in assessing the effect of several factors on the magnitude of CRC worry. Higher education, uncertainty about access to GI specialists, tension-anxiety, and absolute risk were the factors that predicted elevated CRC worry as shown in results section of manuscript \# 2. However, due of the cross-sectional nature of both manuscripts, the direction of causality is unknown. It would be difficult to know whether these factors lead to development of CRC worry, or whether presence 
of CRC worry lead to increased perception of risk for CRC or increased tension-anxiety. Future work using prospective designs will be needed for this purpose.

In conclusion, manuscript \# 1 focused on health behavior component of the SRM whereas manuscript \# 2 focused on the affective representation of the model. The results of these two manuscripts may be combined in order to address the influence of affective representation on health behavior. As discussed before, and from the perspective of the theoretical model, a moderate magnitude of worry may generate healthy behavior (e.g., CRC screening) when people have a clear action plan of what can be done in order to avoid the threat that endangers their health. However, more research is needed in the future to articulate the factors that associated with CRC worry and explain how such factors can be manipulated in order to stimulate the affective representation (e.g., CRC worry) needed to generate health behavior.

Finally, these two manuscripts are expected to fill a gap in research pertaining to the correlation between being an Appalachian and suffering a health disparity that might be due to unawareness, low education, or low health literacy. We expect that these two manuscripts will aid in designing more effective and targeted health interventions in the future that aim to eliminate health disparities related to $\mathrm{CRC}$ incidence in the Appalachian region.

\section{Acknowledgement}

This research study was funded by the National Cancer Institute (grant \# 5P50CA105632-02). 


\section{References}

Abraido-Lanza, A. E., Viladrich, A., Florez, K. R., Cespedes, A., Aguirre, A. N., \& De La Cruz, A. A. (2007). Commentary: Fatalismo reconsidered: A cautionary note for health-related research and practice with latino populations Ethnicity \& Disease, 17(1), 153-158.

Aiken, L. S., Gerend, M. A., \& Jackson, K. M. (2001). Subjective risk and health protective behavior: Cancer screening and cancer prevention. In A. Baum, T. A. Revenson \& J. E. Singer (Eds.), Handbook of health psychology (pp. 727-746) Lawrence Erlbaum Associates.

Ajzen, I. (2002). Perceived behavioral control, self-efficacy, locus of control, and the theory of planned Behavior1 Journal of Applied Social Psychology, 32(4), 665 <last_page> 683. doi:10.1111/j.1559-1816.2002.tb00236.x

American Cancer Society. (2013). Colon cancer statistics. Retrieved July 7th, 2013, from http://www.cancer.org/cancer/colonandrectumcancer/detailedguide/index

American Gastroenterological Association. (2013a). Colorectal cancer prevention and treatment. Retrieved June/27, 2013, from http://www.gastro.org/patient-center/digestive$\underline{\text { conditions/colorectal-cancer\#Prevention }}$

American Gastroenterological Association. (2013b). Symptoms of colorectal cancer. Retrieved 06/21, 2013, from http://www.gastro.org/patient-center/digestive-conditions/colorectalcancer\#Symptoms of Colorectal Cancer 
Andersen, B. L., Cacioppo, J. T., \& Roberts, D. C. (1995). Delay in seeking a cancer diagnosis: Delay stages and psychophysiological comparison processes. British Journal of Social Psychology, 34(1), 33 <last_page> 52. doi:10.1111/j.2044-8309.1995.tb01047.x

Appalachian Regional Commission. (2013). Counties in appalachia. Retrieved 7/04/2012, 2013, from http://www.arc.gov/counties

Armstrong, L. R., Thompson, T., Hall, H. I., Coughlin, S. S., Steele, B., \& Rogers, J. D. (2004). Colorectal carcinoma mortality among appalachian men and women, 1969-1999 Cancer, 101(12), 2851-2858. doi:10.1002/cncr.20667

Bardach, S. H., Schoenberg, N. E., Fleming, S. T., \& Hatcher, J. (2011). Relationship between colorectal cancer screening adherence and knowledge among vulnerable rural residents of appalachian kentucky. Cancer Nursing, 35(4), 288-294.

doi:10.1097/NCC.0b013e31822e7859

Baumann, L. (2003). Culture and illness representation. In L. Cameron, \& H. Leventhal (Eds.), The self-regulation of health and illness behaviour. New York: Routledge:

Behringer, B., \& Friedell, G. H. (2006). Appalachia: Where place matters in health. Preventing Chronic Disease, 3(4), A113.

Behringer, B., \& Krishnan, K. (2011). Understanding the role of religion in cancer care in appalachia. Southern Medical Journal, 104(4), 295-296.

Blackley, D., Behringer, B., \& Zheng, S. (2012). Cancer mortality rates in appalachia: Descriptive epidemiology and an approach to explaining differences in outcomes. Journal of 
Community Health, 37(4), 804-813. doi:10.1007/s10900-011-9514-z; 10.1007/s10900-0119514-Z

Blascovich, J., \& Tomaka, J. (1991). Measures of self-esteem. In j. Robinson, P. Shaver \& L. Wrightsman (Eds.), Measures of personality and social psychological attitudes (pp. 115)

Bolin, T. D. (1996). Cost benefit of early diagnosis of colorectal cancer. Scandinavian Journal of Gastroenterology, 31(s220), 142 <last_page> 146. doi:10.3109/00365529609094767

Bollinger, C., Ziliak, J., \& Troske, K. (2011). Down from the mountain: Skill upgrading and wages in appalachia. Journal of Labor Economics, 29(4)

Borkan, j. (1999). Immersion/Crystallization. In B. Crabtree, \& W. Miller (Eds.), Doing qualitative research (Second Edition ed., pp. 179-194). CA: Sage Publications.

Borkovec, T., Robinson, E., Pruzinsky, T., \& DePree, J. (1983). Preliminary exploration of worry: Some characteristics and processes. Behaviour Research and Therapy, 21(1), 9 <last_page> 16. doi:10.1016/0005-7967(83)90121-3

Bowen, D. J., Helmes, A., Powers, D., Andersen, M. R., Burke, W., Mctiernan, A., \& Durfy, S. (2003). Predicting breast cancer screening intentions and behavior with emotion and cognition. Journal of Social and Clinical Psychology, 22(2), $213<$ last_page> 232. doi:10.1521/jscp.22.2.213.22875

Brenes, G. A., \& Paskett, E. D. (2000). Predictors of stage of adoption for colorectal cancer screening. Preventive Medicine, 31(4), 410-416. doi:10.1006/pmed.2000.0729 
Cameron, L., Leventhal, \& Leventhal. (1995). Seeking medical care in response to symptoms and life stress. Psychosomatic Medicine, 57(1), 37-47.

Champion, V. L. (1988). Attitudinal variables related to intention, frequency and proficiency of breast self-examination in women 35 and over. Research in Nursing \& Health, 11(5), 283 <last_page> 291.doi:10.1002/nur.4770110503

Collins, V., Halliday, J., Warren, R., \& Williamson, R. (2000). Cancer worries, risk perceptions and associations with interest in DNA testing and clinic satisfaction in a familial colorectal cancer clinic. Clinical Genetics, 58(6), 460-468.

Coughlin, S. S., Costanza, M. E., Fernandez, M. E., Glanz, K., Lee, J. W., Smith, S. A., . . Blumenthal, D. S. (2006). CDC-funded intervention research aimed at promoting colorectal cancer screening in communities. Cancer, 107(5 Suppl), 1196-1204.

doi:10.1002/cncr.22017

Coyne, C. A., Demian-Popescu, C., \& Friend, D. (2006a). Social and cultural factors influencing health in southern west virginia: A qualitative study. Preventing Chronic Disease, 3(4), A124.

Coyne, C. A., Demian-Popescu, C., \& Friend, D. (2006b). Social and cultural factors influencing health in southern west virginia: A qualitative study. Preventing Chronic Disease, 3(4), A124.

Crotty, M. (1998). The foundation of social research meaning and perspective in social research Allen and Unwin. 
Curran, S. L., Andrykowski, M. A., \& Studts, J. L. (1995). Short form of the profile of mood states (POMS-SF): Psychometric information. Psychological Assessment, 7(1), 80 <last_page> 83. doi:10.1037/1040-3590.7.1.80

Curry, W. J., Lengerich, E. J., Kluhsman, B. C., Graybill, M. A., Liao, J. Z., Schaefer, E. W., . . Dignan, M. B. (2011). Academic detailing to increase colorectal cancer screening by primary care practices in appalachian pennsylvania. BMC Health Services Research, 11, 112. doi:10.1186/1472-6963-11-112

Davis, R. E., Armstrong, D. K., Dignan, M., Norling, G. R., \& Redmond, J. (2006). Evaluation of educational materials on colorectal cancer screening in appalachian kentucky. Preventing Chronic Disease, 3(2), A43.

DeNavas-Walt, C., Proctor, B., \& Smith, J. (2009). Income, poverty, and health insurance coverage in the united states: 2008. ( No. P60-236(RV)). Washington, DC: U.S. Department of Commerce Economics and Statistics Administration U.S. CENSUS BUREAU.

DeSalvo, K., Bloser, N., Reynolds, K., He, J., \& Muntner, P. (2006). Mortality prediction with a single general self-rated health question. Journal of General Internal Medicine, 21(3), 267275.

Diddle, G., \& Denham, S. A. (2010). Spirituality and its relationships with the health and illness of appalachian people. Journal of Transcultural Nursing, 21(2), 175-182. doi: $10.1177 / 1043659609357640$ 
Diefenbach, M. A., \& Leventhal. (1996). The common-sense model of illness representation: Theoretical and practical considerations. Journal of Social Distress and the Homeless, 5(1), 11 <last_page> 38. doi:10.1007/BF02090456

Diefenbach, M. A., Miller, S. M., \& Daly, M. B. (1999). Specific worry about breast cancer predicts mammography use in women at risk for breast and ovarian cancer. Health Psychology, 18(5), 532 <last_page> 536. doi:10.1037/0278-6133.18.5.532

Duncan, C. M. (1992). Persistent poverty in appalachia : Scarce work and rigid stratification. Rural poverty in america (First Edition ed., pp. 111-112). USA: Auburn House (January 30, 1992).

Edberg, M. C. (2007). Essentials of health behavior: Social and behavioral theory in public health (First Edition ed., ) Jones and Bartlett; (April 4, 2007).

Fernandez, M. E., Wippold, R., Torres-Vigil, I., Byrd, T., Freeberg, D., Bains, Y., ... Vernon, S. W. (2008). Colorectal cancer screening among latinos from U.S. cities along the TexasMexico border. Cancer Causes \& Control, 19(2), 195 <last_page> 206. doi:10.1007/s10552-007-9085-6

Fisher, J., Engelhardt, H., Stephens, J., Smith, B., Haydu, G., Indian, R., \& Paskett, E. D. (2012). Cancer-related disparities among residents of appalachia ohio. Journal of Health Disparities Research and Practice, 2(2).

Franklin, M. D., Schlundt, D. G., McClellan, L. H., Kinebrew, T., Sheats, J., Belue, R., .. . Hargreaves, M. (2007). Religious fatalism and its association with health behaviors and 
outcomes American Journal of Health Behavior, 31(6), 563-572.

doi:10.5555/ajhb.2007.31.6.563

Franks, P., Gold, M. R., \& Fiscella, K. (2003). Sociodemographics, self-rated health, and mortality in the US. Social Science \& Medicine, 56(12), 2505 <last_page> 2514. doi:10.1016/S0277-9536(02)00281-2

Gorin, S. S. (2005). Correlates of colorectal cancer screening compliance among urban hispanics. Journal of Behavioral Medicine, 28(2), 125-137.

Greiner, K. A., Born, W., Nollen, N., \& Ahluwalia, J. S. (2005). Knowledge and perceptions of colorectal cancer screening among urban african americans. Journal of General Internal Medicine, 20(11), 977-983. doi:10.1111/j.1525-1497.2005.00165.x

Hamrick, N., \& Diefenbach, M. A. (2006). Religion and spirituality among patients with localized prostate cancer. Palliative \& Supportive Care, 4(04) doi:10.1017/S1478951506060457

Hatcher, J., Dignan, M. B., \& Schoenberg, N. (2011). How do rural health care providers and patients view barriers to colorectal cancer screening? insights from appalachian kentucky. The Nursing Clinics of North America, 46(2), 181-92, vi. doi:10.1016/j.cnur.2011.02.001; 10.1016/j.cnur.2011.02.001

Hay, J., Buckley, T. R., \& Ostroff, J. S. (2005). The role of cancer worry in cancer screening: A theoretical and empirical review of the literature. Psycho-Oncology, 14(7), 517-534. doi:10.1002/pon.864 
Hay, J., Coups, E., \& Ford, J. (2006). Predictors of perceived risk for colon cancer in a national probability sample in the united states. Journal of Health Communication, 11 Suppl 1, 7192. doi:10.1080/10810730600637376

Hay, J., McCaul, K. D., \& Magnan, R. E. (2006). Does worry about breast cancer predict screening behaviors? A meta-analysis of the prospective evidence. Preventive Medicine, 42(6), 401-408. doi:10.1016/j.ypmed.2006.03.002

Hendryx, M. (2011). Poverty and mortality disparities in central appalachia: Mountaintop mining and environmental justice. Journal of Health Disparities Research and Practice, 4(3), 4453.

Hill, D., Gardner, G., \& Rassaby, J. (1985). Factors predisposing women to take precautions against breast and cervix cancer. Journal of Applied Social Psychology, 15(1), 59 <last_page> 79.doi:10.1111/j.1559-1816.1985.tb00894.x

Hopenhayn, C., Moore, D. B., Huang, B., Redmond, J., Tucker, T. C., Kryscio, R. J., \& Boissonneault, G. A. (2004). Patterns of colorectal cancer incidence, risk factors, and screening in kentucky. Southern Medical Journal, 97(3), 216-223.

Huang, B., Wyatt, S. W., Tucker, T. C., \& Bottorff, D. (2002). Cancer death rates --- appalachia, 1994--1998. MMWR, 51(24), 527-529.

Huttlinger, K., Schaller-Ayers, J., \& Lawson, T. (2004). Health care in appalachia: A populationbased approach. Public Health Nursing, 21(2), 103 <last_page> 110. doi:10.1111/j.07371209.2004.021203.x 
Kaplan, G. A., \& Camacho, T. (1983). Perceived health and mortality: A nine-year follow-up of the human population laboratory cohort. American Journal of Epidemiology, 117(3), 292304.

Keeler, E. B., Sloss, E. M., Brook, R. H., Operskalski, B. H., Goldberg, G. A., \& Newhouse, J. P. (1987). Effects of cost sharing on physiological health, health practices, and worry. Health Services Research, 22(3), 279-306.

Kelly, K. M., Phillips, C. M., Jenkins, C., Norling, G., White, C., Jenkins, T., . . Dignan, M. (2007). Physician and staff perceptions of barriers to colorectal cancer screening in appalachian kentucky. Cancer Control, 14(2), 167-175.

Kim, K. H., \& Sobal, J. (2004). Religion, social support, fat intake and physical activity. Public Health Nutrition, 7(6), 773-781.

Kirscht, J. P., Haefner, D. P., Kegeles, S. S., \& Rosenstock, I. M. (1966). A national study of health beliefs. Journal of Health and Human Behavior, 7(4), 248-254.

Koloski, N. A., Talley, N. J., \& Boyce, P. M. (2001). Predictors of health care seeking for irritable bowel syndrome and nonulcer dyspepsia: A critical review of the literature on symptom and psychosocial factors. The American Journal of Gastroenterology, 96(5), 1340-1349. doi:10.1111/j.1572-0241.2001.03789.x

Lane, N., Lutz, A., \& Baker, k. (2012). Health care costs and access disparities in appalachia. ( No. CO-16835-2010). 1666 Connecticut Avenue NW Suite 700 Washington, DC 200091068: Appalachian Regional Commission. 
Lebo, M. A., \& Nesselroade, J. R. (1978). Intraindividual differences dimensions of mood change during pregnancy identified in five P-technique factor analyses. Journal of Research in Personality, 12(2), 205 <last_page> 224. doi:10.1016/0092-6566(78)90098-3

Lengerich, E. J., Rubio, A., Brown, P. K., Knight, E. A., \& Wyatt, S. W. (2006). Results of coordinated investigations of a national colorectal cancer education campaign in appalachia. Preventing Chronic Disease, 3(2), A32.

Lerman, C., Kash, K., \& Stefanek, M. (1994). Younger women at increased risk for breast cancer: Perceived risk, psychological well-being,..., Journal of the National Cancer Institute. Monographs, 16, 171-176.

Lerman, C., Trock, B., Rimer, B. K., Jepson, C., Brody, D., \& Boyce, A. (1991). Psychological side effects of breast cancer screening. Health Psychology, 10(4), 259-267.

Leventhal. (1970). Findings and theory in the study of fear communications. Advances in Experimental Social Psychology, 5, 119-186.

Leventhal, Benyamini, Y., Brownlee, S., Diefenbach, M., Leventhal, Patrick-Miller, L., \& Robitaille, C. (1997). Illness representations: Theoretical foundations. In K. Petrie, \& J. Weinman (Eds.), Perceptions of health \& illnes: Current research and applications (pp. 1946)

Leventhal, Brisette, I., \& Leventhal. (2003a). The common-sense model of self regulation of health and illness. In L. Cameron, \& H. Leventhal (Eds.), The self-regulation of health and illness behaviour (pp. 42) 
Leventhal, Brisette, I., \& Leventhal. (2003b). The common-sense model of self-regulation of health and illness. In L. Cameron, \& L. Howard (Eds.), The self-regulation of health and illness behavior. (). New York: Routledge.

Leventhal, \& Cameron, L. (1987). Behavioral theories and the problem of compliance Patient Education and Counseling, 10(2), 117 <last_page> 138. doi:10.1016/0738-3991(87)900930

Leventhal, Diefenbach, M., \& Leventhal. (1992). Illness cognition: Using common sense to understand treatment adherence and affect cognition interactions. Cognitive Therapy and Research, 16(2), 143-163. doi:10.1007/BF01173486

Leventhal, Meyer, \& Nerenz. (1980). The common sense model of illness danger. In S. Rachman (Ed.), Medical psychology (pp. 7-30). Pergamon, New York:

Levin, B., Lieberman, D. A., McFarland, B., Andrews, K. S., Brooks, D., Bond, J., .. . Winawer, S. J. (2008). Screening and surveillance for the early detection of colorectal cancer and adenomatous polyps, 2008: A joint guideline from the american cancer society, the US multi-society task force on colorectal cancer, and the american college of radiology Gastroenterology, 134(5), 1570 <last_page> 1595. doi:10.1053/j.gastro.2008.02.002

Lewis, R. L., \& Billings, D. B. (1997). Appalachian culture and economic development. Journal of Appalachian Studies, 3(1), 43-69.

Lieberman, D. A., Weiss, D. G., Bond, J. H., Ahnen, D. J., Garewal, H., \& Chejfec, G. (2000). Use of colonoscopy to screen asymptomatic adults for colorectal cancer. veterans affairs 
cooperative study group 380 The New England Journal of Medicine, 343(3), 162-168. doi:10.1056/NEJM200007203430301

Lipkus, I. M., Kuchibhatla, M., McBride, C. M., Bosworth, H. B., Pollak, K. I., Siegler, I. C., \& Rimer, B. K. (2000). Relationships among breast cancer perceived absolute risk, comparative risk, and worries. Cancer Epidemiology, Biomarkers \& Prevention, 9(9), 973975.

McCaul, K. D., Branstetter, A. D., O'Donnell, S. M., Jacobson, K., \& Quinlan, K. B. (1998). A descriptive study of breast cancer worry. Journal of Behavioral Medicine, 21(6), 565 <last_page> 579. doi:10.1023/A:1018748712987

McCaul, K. D., Schroeder, D. M., \& Reid, P. A. (1996). Breast cancer worry and screening: Some prospective data. Health Psychology, 15(6), 430 <last_page> 433. doi:10.1037/02786133.15.6.430

McCullough, M. E., Hoyt, W. T., Larson, D. B., Koenig, H. G., \& Thoresen, C. (2000). Religious involvement and mortality: A meta-analytic review. Health Psychology, 19(3), 211-222.

McNair, D. M., Lorr, M., \& Droppleman, L. (1971). Profile of mood states (POMS $\left.{ }^{\mathrm{TM}}\right)$. San Diego, CA: Educational and Industrial Testing Services.

McQueen, A., Vernon, S. W., Meissner, H. I., \& Rakowski, W. (2008). Risk perceptions and worry about cancer: Does gender make a difference? Journal of Health Communication, 13(1), 56-79. doi:10.1080/10810730701807076 
Miller, A. M., \& Champion, V. L. (1993). Mammography in women > or = 50 years of age. predisposing and enabling characteristics. Cancer Nursing, 16(4), 260-269.

Monteros, K. E. d. L., \& Gallo, L. C. (2011). The relevance of fatalism in the study of latinas' cancer screening behavior: A systematic review of the literature. International Journal of Behavioral Medicine, 18(4), 310-318. doi:10.1007/s12529-010-9119-4

Morgan, P. D., Tyler, I. D., \& Fogel, J. (2008). Fatalism revisited. Seminars in Oncology Nursing, 24(4), 237-245. doi:10.1016/j.soncn.2008.08.003

Myers, R. E., Ross, E., Jepson, C., Wolf, T., Balshem, A., Millner, L., \& Leventhal, H. (1994). Modeling adherence to colorectal cancer screening. Preventive Medicine, 23(2), 142-151. doi:10.1006/pmed.1994.1020

Natale-Pereira, A., Marks, J., Vega, M., Mouzon, D., Hudson, S. V., \& Salas-Lopez, D. (2008). Barriers and facilitators for colorectal cancer screening practices in the latino community: Perspectives from community leaders. Cancer Control, 15(2), 157-165.

O'Leary, A. (1985). Self-efficacy and health Behaviour Research and Therapy, 23(4), 437 <last_page> 451.doi:10.1016/0005-7967(85)90172-X

Paskett, E. D., Llanos, A. A., Young, G. S., Pennell, M. L., Lee, C. J., \& Katz, M. L. (2013). Correlates of colorectal cancer screening among residents of ohio appalachia. Journal of Community Health, doi:10.1007/s10900-013-9683-z

U. S. public law, Pub. L. No. 111-148, §2702, 124 Stat. 119, 318-319. 111th United States Congress; (2010). 
Pheley, A. M., Holben, D. H., Graham, A. S., \& Simpson, C. (2002). Food security and perceptions of health status: A preliminary study in rural appalachia. The Journal of Rural Health, 18(3), 447 <last_page> 453. doi:10.1111/j.1748-0361.2002.tb00909.x

Philip, E. J., DuHamel, K., \& Jandorf, L. (2010). Evaluating the impact of an educational intervention to increase $\mathrm{CRC}$ screening rates in the african american community: A preliminary study. Cancer Causes \& Control : CCC, 21(10), 1685-1691. doi:10.1007/s10552-010-9597-3

Photiadis, J. D. (1977). Religion: A persistent institution in a changing appalachia. Review of Religious Research, 19(1), 32-42.

Pollard, K., \& Jacobsen, L. A. (2011). THE APPALACHIAN REGION IN 2010: A CENSUS DATA OVERVIEW, chartbook. ( No. Prepared for the Appalachian Regional Commission Under Contract \#CO-16506-09).Population Reference Bureau. Retrieved from http://www.prb.org.www.libproxy.wvu.edu/pdf12/appalachia-census-chartbook-2011.pdf

Pollard, K., \& Jacobsen, L. A. (2013). The appalachian region: A data overview from the 20072011 american community survey. Appalachian Regional Commission.

Powe, B. D. (1995). Fatalism among elderly african americans. effects on colorectal cancer screening Cancer Nursing, 18(5), 385-392.

Powe, B. D., Cooper, D. L., Harmond, L., Ross, L., Mercado, F. E., \& Faulkenberry, R. (2009). Comparing knowledge of colorectal and prostate cancer among african american and hispanic men. Cancer Nursing, 32(5), 412-417. doi:10.1097/NCC.0b013e3181aaf10e 
Powe, B. D., \& Finnie, R. (2003). Cancer fatalism: The state of the science. Cancer Nursing, 26(6), 454-65; quiz 466-7.

Powell, L. H., Shahabi, L., \& Thoresen, C. E. (2003). Religion and spirituality. linkages to physical health. The American Psychologist, 58(1), 36-52.

Price, M. A., Butow, P. N., Lo, S. K., \& Wilson, J. (2007). Predictors of cancer worry in unaffected women from high risk breast cancer families: Risk perception is not the primary issue. Journal of Genetic Counseling, 16(5), 635-644. doi:10.1007/s10897-007-9105-4

Reiter, P. L., Katz, M. L., Oliveri, J. M., Young, G. S., Llanos, A. A., \& Paskett, E. D. (2013). Validation of self-reported colorectal cancer screening behaviors among appalachian residents. Public Health Nursing, 30(4), 312 <last_page> 322. doi:10.1111/phn.12038

Risjord, M., Dunbar, S., \& Moloney, M. (2002). A new foundation for methodological triangulation. Journal of Nursing Scholarship, 34(3), 269-275.

Robberson, M. R., \& Rogers, R. W. (1988). Beyond fear appeals: Negative and positive persuasive appeals to health and self-esteem. Journal of Applied Social Psychology, 18(3), 277 <last_page> 287. doi:10.1111/j.1559-1816.1988.tb00017.x

Rogers, R. W. (1983). Cognitive and physiological processes in attitude change. In J. Cacioppo, \& R. Petty (Eds.), A revised theory of protection motivation (pp. 153-176). Guilford Press: New York: Social Psychophysiology. 
Rowles, G. D. (1991). Changing health culture in rural appalachia: Implications for serving the elderly. Journal of Aging Studies, 5(4), 375 <last_page> 389. doi:10.1016/08904065(91)90017-M

Royse, D., \& Dignan, M. (2001). Fatalism and cancer screening in appalachian kentucky. Family \& Community Health, 34(2), 126-133.

Safer, M. A., Tharps, Q. J., Jackson, T. C., \& Leventhal, H. (1979). Determinants of three stages of delay in seeking care at a medical clinic. Medical Care, 17(1), 11-29.

Sanders Thompson, V. L., Lewis, T., \& Williams, S. L. (2011). Refining the use of cancerrelated cultural constructs among african americans. Health Promotion Practice, doi:10.1177/1524839911399431

Scheier, M. F., \& Carver, C. S. (2003). Goals and confidence as self-regulatory elements underlying health and illness behaviour. In L. Cameron, \& H. Leventhal (Eds.), The selfregulation of health and illness behaviour (pp. 17)

Seeff, L. C., Nadel, M. R., Klabunde, C. N., Thompson, T., Shapiro, J. A., Vernon, S. W., \& Coates, R. J. (2004). Patterns and predictors of colorectal cancer test use in the adult U.S. population. Cancer, 100(10), 2093 <last_page> 2103. doi:10.1002/cncr.20276

Shacham, S. (1983). A shortened version of the profile of mood states. Journal of Personality Assessment, 47(3), 305 <last_page> 306. doi:10.1207/s15327752jpa4703_14

Shell, R., \& Tudiver, F. (2004). Barriers to cancer screening by rural appalachian primary care providers The Journal of Rural Health, 20(4), 368-373. 
Shelton, R. C., Jandorf, L., Ellison, J., Villagra, C., \& DuHamel, K. N. (2011). The influence of sociocultural factors on colonoscopy and FOBT screening adherence among low-income hispanics. Journal of Health Care for the Poor and Underserved, 22(3), 925-944.

Smith-Howell, E. R., Rawl, S. M., Champion, V. L., Skinner, C. S., Springston, J., Krier, C., .. . Myers, L. J. (2011). Exploring the role of cancer fatalism as a barrier to colorectal cancer screening. Western Journal of Nursing Research, 33(1), 140-141. doi: $10.1177 / 0193945910378810$

Spitler, H. D., Mayo, R. M., \& Parker, V. G. (2001). Patterns of breast, cervical, colorectal, and prostate cancer in the appalachian region of south carolina. Ethnicity \& Disease, 11(1), 5159.

Stensland, J., Mueller, C., \& Sutton, J. (2002). An analysis of the financial conditions of health care institutions in the appalachian region and their economic impacts. Washington, D.C.: Appalachian Regional Commission.

Strawbridge, W. J., Shema, S. J., Cohen, R. D., \& Kaplan, G. A. (2001). Religious attendance increases survival by improving and maintaining good health behaviors, mental health, and social relationships. Annals of Behavioral Medicine,23(1), 68-74. doi:10.1207/S15324796ABM2301_1

Tarasenko, Y., Fleming, S. T., \& Schoenberg, N. E. (2013). The relationship between perceived burden of chronic conditions and colorectal cancer screening among appalachian residents. The Journal of Rural Health, doi:10.1111/jrh.12035 
Tarasenko, Y., \& Schoenberg, N. E. (2011). Colorectal cancer screening among rural appalachian residents with multiple morbidities. Rural and Remote Health, 11(1), 1553.

Tessaro, I., Mangone, C., Parkar, I., \& Pawar, V. (2006). Knowledge, barriers, and predictors of colorectal cancer screening in an appalachian church population. Preventing Chronic Disease, 3(4), A123.

U.S. Preventive Services Task Force. (2008). Guide to clinical preventive services U.S. preventive services task force. screening for colorectal cancer: U.S. preventive services task force recommendation statement. AHRQ publication 08-05124-EF-3. Retrieved August 8, 2012, from http://www.uspreventiveservicestaskforce.org/uspstf08/colocancer/colors.htm

United States Department of Agriculture. (2013). Economic research services. rural-urban continuum codes; Retrieved 12/6/2012, 2013, from http://www.ers.usda.gov/dataproducts/rural-urban-continuum-codes.aspx\#.UdXxevm87oJ

Vanderpool, R. C., \& Huang, B. (2010). Cancer risk perceptions, beliefs, and physician avoidance in appalachia: Results from the 2008 HINTS survey. Journal of Health Communication, 15(3), 78-91.

Vernon, S. W., Myers, R. E., Tilley, B. C., \& Li, S. (2001). Factors associated with perceived risk in automotive employees at increased risk of colorectal cancer. Cancer Epidemiology, Biomarkers \& Prevention, 10(1), 35-43. 
Wallston, B. S.,Wallston, K. A., Kaplan, G. D., Maides, S. A. (1976). Development and validation of the Health Locus of Control (HLC) Scale. Journal of Consulting and Clinical

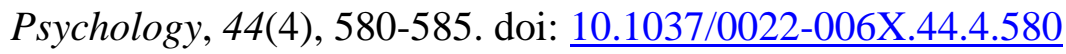

Ward, A. J., Coffey Kluhsman, B., Lengerich, E. J., \& Piccinin, A. M. (2006). The impact of cancer coalitions on the dissemination of colorectal cancer materials to community organizations in rural appalachia. Preventing Chronic Disease, 3(2), A55.

Watts, B. G., Vernon, S. W., Myers, R. E., \& Tilley, B. C. (2003). Intention to be screened over time for colorectal cancer in male automotive workers. Cancer Epidemiology, Biomarkers \& Prevention, 12(4), 339-349.

Witte, K. (1992). Putting the fear back into fear appeals: The extended parallel process model. Communication Monographs, 59(4), 329 <last_page> 349. doi:10.1080/03637759209376276

Worthington, E. L., Wade, N. G., Hight, T. L., Ripley, J. S., McCullough, M. E., Berry, J. W., . . . O'Connor, L. (2003). The religious commitment inventory--10: Development, refinement, and validation of a brief scale for research and counseling. American Psychological Association, 50(1), 84-96.

Zajac, L. E., Klein, W. M., \& McCaul, K. D. (2006). Absolute and comparative risk perceptions as predictors of cancer worry: Moderating effects of gender and psychological distress. Journal of Health Communication, 11 Suppl 1, 37-49. doi:10.1080/10810730600637301 
Table 1

Categorical Variables Distribution and Chi-square Analysis with the Dependent Variable

\begin{tabular}{|c|c|c|c|c|c|c|}
\hline & & $\begin{array}{c}\text { Total } \\
\text { (column\%) }\end{array}$ & $\begin{array}{l}\text { No worry } \\
\text { group } \\
\text { (Row\%) }\end{array}$ & $\begin{array}{l}\text { Some } \\
\text { worry } \\
\text { group } \\
\text { (Row\%) }\end{array}$ & Test Statistics & Sig. \\
\hline \multirow{2}{*}{ CRC Worry } & No Worry & $74(55 \%)$ & & & & \\
\hline & Some Worry & $60(45 \%)$ & & & & \\
\hline \multirow[b]{2}{*}{ Race/Ethnicity } & Non-Hispanic White & $115(86 \%)$ & $61(53 \%)$ & $54(47 \%)$ & \multirow{2}{*}{$\begin{array}{c}x^{2}(1, N=134)= \\
1.56, p=0.32\end{array}$} & \\
\hline & $\begin{array}{l}\text { Other Races, Mixed Races, or } \\
\text { Hispanic ethnicity }\end{array}$ & $19(14 \%)$ & $13(68 \%)$ & $6(32 \%)$ & & \\
\hline \multirow{2}{*}{ Appalachian Identity } & No & $90(72 \%)$ & $53(59 \%)$ & $37(41 \%)$ & \multirow{2}{*}{$\begin{array}{c}x^{2}(1, N=125)= \\
0.22, p=0.69\end{array}$} & \\
\hline & Yes & $35(28 \%)$ & $19(54 \%)$ & $16(46 \%)$ & & \\
\hline \multirow{2}{*}{ Medicare } & No & $116(87 \%)$ & $65(56 \%)$ & $51(44 \%)$ & \multirow{2}{*}{$\begin{array}{c}x^{2}(1, N=133)= \\
0.48, p=0.60\end{array}$} & \\
\hline & Yes & $17(13 \%)$ & $8(47 \%)$ & $9(53 \%)$ & & \\
\hline \multirow{2}{*}{ Medicaid } & No & $65(50 \%)$ & $35(54 \%)$ & $30(46 \%)$ & \multirow{2}{*}{$\begin{array}{c}x^{2}(1, N=133)= \\
0.19, p=0.73\end{array}$} & \\
\hline & Yes & $66(14 \%)$ & $38(58 \%)$ & $28(42 \%)$ & & \\
\hline \multirow{2}{*}{ Health Insurance } & No & $31(23 \%)$ & $17(55 \%)$ & $14(45 \%)$ & \multirow{2}{*}{$\begin{array}{l}x^{2}(1, N=134)< \\
0.05, p=1.000\end{array}$} & \\
\hline & Yes & $103(77 \%)$ & $57(55 \%)$ & $46(45 \%)$ & & \\
\hline \multirow{2}{*}{$\begin{array}{l}\text { Belong to a } \\
\text { Religious } \\
\text { Organization }\end{array}$} & No & $80(61 \%)$ & $43(54 \%)$ & $37(46 \%)$ & \multirow{2}{*}{$\begin{array}{c}x^{2}(1, N=133)= \\
0.63, p=0.47\end{array}$} & \\
\hline & Yes & $51(39 \%)$ & $31(61 \%)$ & $20(39 \%)$ & & \\
\hline \multirow{3}{*}{$\begin{array}{l}\text { Perceived } \\
\text { Vulnerability (Odds } \\
\text { get cancer Again) }\end{array}$} & Higher & $30(23 \%)$ & $13(43 \%)$ & $17(57 \%)$ & \multirow{3}{*}{$\begin{array}{c}x^{2}(2, N=128)= \\
8.82, p<0.05\end{array}$} & \multirow{3}{*}{ * } \\
\hline & The Same & $73(57 \%)$ & $36(49 \%)$ & $37(51 \%)$ & & \\
\hline & Lower & $25(20 \%)$ & $20(80 \%)$ & $5(20 \%)$ & & \\
\hline \multirow{2}{*}{ Poverty } & Above the poverty line (Not poor) & $46(34 \%)$ & $24(52 \%)$ & $22(48 \%)$ & \multirow{2}{*}{$\begin{array}{c}x^{2}(1, N=134)= \\
0.26, p=0.72\end{array}$} & \\
\hline & Below the poverty line (Poor) & $88(66 \%)$ & $50(57 \%)$ & $38(43 \%)$ & & \\
\hline \multirow[b]{2}{*}{ Education Level } & $\begin{array}{l}\text { GED or 12th grade, or less } \\
\text { (Preschool, Kindergarten - 11th } \\
\text { grade) }\end{array}$ & $77(57 \%)$ & $48(62 \%)$ & $29(38 \%)$ & \multirow[b]{2}{*}{$\begin{array}{c}x^{2}(1, N=134)= \\
3.71, p=0.08\end{array}$} & \multirow[b]{2}{*}{ * } \\
\hline & $\begin{array}{l}\text { Technical, Trade Degree, } \\
\text { Associate, Bachelor's, Master's, } \\
\text { Professional, Doctorate degrees, } \\
\text { or Some years of that }\end{array}$ & $57(43 \%)$ & $26(46 \%)$ & $31(54 \%)$ & & \\
\hline \multirow{3}{*}{ Marital Status } & Married & $38(29 \%)$ & $20(53 \%)$ & $18(47 \%)$ & \multirow{3}{*}{$\begin{array}{c}x^{2}(2, N=133)= \\
0.28, p=0.87\end{array}$} & \\
\hline & Divorced, Widowed, Separated & $54(41 \%)$ & $30(56 \%)$ & $24(44 \%)$ & & \\
\hline & $\begin{array}{l}\text { Single, never been married, or a } \\
\text { member of unmarried couple }\end{array}$ & $41(31 \%)$ & $24(59 \%)$ & $17(41 \%)$ & & \\
\hline \multirow{3}{*}{ Income } & Equal or less than 10,000 & $64(48 \%)$ & $35(55 \%)$ & $29(45 \%)$ & \multirow{3}{*}{$\begin{array}{c}x^{2}(2, N=134)= \\
0.14, p=0.94\end{array}$} & \\
\hline & $10,001-20,000$ & $40(30 \%)$ & $23(58 \%)$ & $17(43 \%)$ & & \\
\hline & Equal or more than 20,001 & $30(22 \%)$ & $16(53 \%)$ & $14(47 \%)$ & & \\
\hline \multirow{3}{*}{ Occupational Status } & Employed & $56(42 \%)$ & $37(66 \%)$ & $19(34 \%)$ & & \\
\hline & Unemployed, Retired, or Disabled & $61(46 \%)$ & $29(48 \%)$ & $32(52 \%)$ & $x^{2}(2, N=133)=$ & * \\
\hline & Housewife or Student & $16(12 \%)$ & $7(44 \%)$ & $9(56 \%)$ & & \\
\hline & Easy & $22(17 \%)$ & $9(41 \%)$ & $13(59 \%)$ & & \\
\hline $\begin{array}{l}\text { Access to } \\
\text { gastroenterologist }\end{array}$ & $\begin{array}{l}\text { Neither easy nor difficult/Do Not } \\
\text { Know }\end{array}$ & $76(58 \%)$ & $50(66 \%)$ & $26(34 \%)$ & $\begin{array}{c}x^{2}(2, N=132)= \\
9.17, p<0.05\end{array}$ & * \\
\hline & Difficult & $34(26 \%)$ & $13(38 \%)$ & $21(62 \%)$ & & \\
\hline Dorroived Holth & Excellent, Very good, or Good & $72(54 \%)$ & $43(60 \%)$ & $29(40 \%)$ & $x^{2}(1, N=133)=$ & \\
\hline Percelved Health & Fair, Poor, or Very Poor & $61(46 \%)$ & $30(49 \%)$ & $31(51 \%)$ & $1.48, p=0.29$ & \\
\hline Perceived & $\begin{array}{l}\text { Not at all, a little bit, moderately, } \\
\text { or quite a bit }\end{array}$ & $41(31 \%)$ & $28(68 \%)$ & $13(32 \%)$ & $x^{2}(1, N=132)=$ & * \\
\hline Seriousness of CRC & Very Much & $91(69 \%)$ & $45(49 \%)$ & $46(51 \%)$ & & \\
\hline Perceived & Not at all, a little bit, moderately, & $69(52 \%)$ & $43(62 \%)$ & $26(38 \%)$ & $x^{2}(1, N=133)=$ & * \\
\hline
\end{tabular}




\begin{tabular}{|c|c|c|c|c|c|c|}
\hline \multirow[t]{2}{*}{ Deadliness of CRC } & or quite a bit & & & & \multirow[t]{2}{*}{$3.20, p=0.08$} & \\
\hline & Very Much & $64(48 \%)$ & $30(47 \%)$ & $34(53 \%)$ & & \\
\hline \multirow{2}{*}{$\begin{array}{l}\text { Try to Prevent } \\
\text { Illness Through a } \\
\text { Healthy Lifestyle }\end{array}$} & $\begin{array}{l}\text { Neither agree nor disagree, } \\
\text { Disagree, or strongly disagree }\end{array}$ & $50(38 \%)$ & $30(60 \%)$ & $20(40 \%)$ & \multirow{2}{*}{$\begin{array}{c}x^{2}(1, N=132)= \\
0.51, p=0.59\end{array}$} & \\
\hline & Agree or strongly agree & $82(62 \%)$ & $44(54 \%)$ & $38(46 \%)$ & & \\
\hline \multirow{2}{*}{$\begin{array}{l}\text { Try to Prevent } \\
\text { Illness by Having } \\
\text { Regular Check-ups }\end{array}$} & $\begin{array}{l}\text { Neither agree nor disagree, } \\
\text { Disagree, or strongly disagree }\end{array}$ & $46(35 \%)$ & $27(59 \%)$ & $19(41 \%)$ & \multirow{2}{*}{$\begin{array}{c}x^{2}(1, N=132)= \\
0.20, p=0.72\end{array}$} & \\
\hline & Agree or strongly agree & $86(65 \%)$ & $47(55 \%)$ & $39(45 \%)$ & & \\
\hline \multirow{2}{*}{$\begin{array}{l}\text { Chances Be Among } \\
\text { Those Who }\end{array}$} & Get Colon Cancer & $31(27 \%)$ & $8(26 \%)$ & $23(74 \%)$ & \multirow{2}{*}{$\begin{array}{l}x^{2}(1, N=116)= \\
13.85, p<0.001\end{array}$} & \multirow[t]{2}{*}{ *** } \\
\hline & Do Not Get Colon Cancer & $85(73 \%)$ & $55(65 \%)$ & $30(35 \%)$ & & \\
\hline \multirow{3}{*}{$\begin{array}{l}\text { Compared with } \\
\text { Others at same age, } \\
\text { Likelihood of Getting } \\
\text { Colon Cancer in } \\
\text { Lifetime }\end{array}$} & $\begin{array}{l}\text { Below Average or Much Below } \\
\text { Average }\end{array}$ & $36(28 \%)$ & $28(78 \%)$ & $8(22 \%)$ & \multirow{3}{*}{$\begin{array}{l}x^{2}(2, N=130)= \\
14.54, p<0.05\end{array}$} & \multirow{3}{*}{ * } \\
\hline & Same & $72(55 \%)$ & $38(53 \%)$ & $34(47 \%)$ & & \\
\hline & $\begin{array}{l}\text { Above Average or Much Above } \\
\text { Average }\end{array}$ & $22(17 \%)$ & $6(27 \%)$ & $16(73 \%)$ & & \\
\hline \multirow{2}{*}{$\begin{array}{l}\text { Likelihood of Having } \\
\text { Colon Cancer }\end{array}$} & No, Not at all & $39(30 \%)$ & $32(82 \%)$ & $7(18 \%)$ & \multirow{2}{*}{$\begin{array}{l}x^{2}(1, N=129)= \\
16.48, p<0.001\end{array}$} & \multirow{2}{*}{$* * *$} \\
\hline & Yes, There is Likelihood & $90(70 \%)$ & $39(43 \%)$ & $51(57 \%)$ & & \\
\hline \multirow{3}{*}{$\begin{array}{l}\text { Frequency of } \\
\text { Attending Religious } \\
\text { Services }\end{array}$} & Once or more every week & $32(25 \%)$ & $19(59 \%)$ & $13(41 \%)$ & \multirow{3}{*}{$\begin{array}{c}x^{2}(2, N=127)= \\
4.56, p=0.10\end{array}$} & \multirow{3}{*}{ * } \\
\hline & Less than once a week & $53(42 \%)$ & $24(45 \%)$ & $29(55 \%)$ & & \\
\hline & Never & $42(33 \%)$ & $28(67 \%)$ & 14(33\%) & & \\
\hline
\end{tabular}

${ }^{* * \star}$. Correlation is significant at the 0.001 level (2-tailed).

**. Correlation is significant at the 0.01 level (2-tailed).

*. Correlation is significant at the 0.10 level (2-tailed). 
Table 2

Continuous Variables Distribution and t-test Analysis with the Dependent Variable

\begin{tabular}{|c|c|c|c|c|c|}
\hline & & No worry group & Some worry group & Test Statistics & Sig. \\
\hline $\begin{array}{l}\text { Chances of } \\
\text { Getting Colon } \\
\text { Cancer at the } \\
\text { General } \\
\text { Population }\end{array}$ & $\begin{array}{l}\text { Perceived Population } \\
\text { Chances (0\%-100\%) }\end{array}$ & $M=39.99(S D=19.56)$ & $\begin{array}{c}M=51.59 \\
(S D=17.13)\end{array}$ & $t(120)=-3.45, p<0.05$ & * \\
\hline $\begin{array}{l}\text { Personal } \\
\text { Chances of } \\
\text { Getting } \\
\text { Cancer } \\
\text { Before the } \\
\text { Age of } 70\end{array}$ & $\begin{array}{l}\text { Perceived Personal } \\
\text { Vulnerability (0\%-100\%) }\end{array}$ & $M=33.00(S D=23.42)$ & $\begin{array}{c}M=47.04 \\
(S D=24.05)\end{array}$ & $t(121)=-3.27, p<0.05$ & * \\
\hline Age & In Years & $M=39.54(S D=12.02)$ & $\begin{array}{c}M=40.93 \\
(S D=12.22)\end{array}$ & $t(122)=-0.63, p=0.53$ & \\
\hline \multirow{2}{*}{$\begin{array}{l}\text { Religious } \\
\text { Commitment } \\
\text { Index }\end{array}$} & Intrapersonal Sub-scale & $\mathrm{M}=12.07(\mathrm{SD}=6.52)$ & $M=12.50(S D=5.97)$ & $t(132)=-0.40, p=0.69$ & \\
\hline & Interpersonal Sub-Scale & $M=3.15(S D=0.94)$ & $M=3.13(S D=0.78)$ & $t(132)=0.17, p=0.87$ & \\
\hline \multirow{6}{*}{$\begin{array}{l}\text { Profile of } \\
\text { Mood States } \\
\text { (POMS) }\end{array}$} & Tense Sub-Scale & $\mathrm{M}=1.48(\mathrm{SD}=0.34)$ & $M=1.61(S D=0.34)$ & $t(132)=-2.17, p<0.05$ & * \\
\hline & Anger Sub-Scale & $M=1.50(S D=0.34)$ & $M=1.51(S D=0.33)$ & $t(132)=-0.23, p=0.82$ & \\
\hline & Depression Sub-Scale & $\mathrm{M}=1.42(\mathrm{SD}=0.37)$ & $\mathrm{M}=1.49(\mathrm{SD}=0.37)$ & $t(132)=-1.03, p=0.31$ & \\
\hline & Confusion Sub-Scale & $\mathrm{M}=1.41(\mathrm{SD}=0.25)$ & $\mathrm{M}=1.49(\mathrm{SD}=0.29)$ & $t(132)=-1.74, p=0.08$ & * \\
\hline & Vigor Sub-Scale & $\mathrm{M}=2.56(\mathrm{SD}=0.88)$ & $\mathrm{M}=2.37(\mathrm{SD}=0.86)$ & $t(132)=1.25, p=0.22$ & \\
\hline & Fatigue Sub-Scale & $\mathrm{M}=2.62(\mathrm{SD}=1.12)$ & $\mathrm{M}=2.96(\mathrm{SD}=1.17)$ & $t(132)=-1.68, p=0.09$ & * \\
\hline Fatalism & Sum of Scale & $\mathrm{M}=1.76(\mathrm{SD}=1.17)$ & $\mathrm{M}=2.00(\mathrm{SD}=0.96)$ & $t(131)=-1.26, p=0.21$ & \\
\hline
\end{tabular}


Table 3

Step 14 in the Backward Stepwise Binary Logistic Regression, where only variable with p-value $\leq 0.05$ are kept

\begin{tabular}{|c|l|c|c|c|c|}
\hline \multicolumn{1}{|c|}{ Variable } & Model Log & Change in -2 Log & df & Sig. of the \\
\hline \multirow{5}{*}{} & Education & -48.138 & 14.385 & 1 & .000 \\
\cline { 2 - 6 } & Access to Gastroenterologist & -47.017 & 12.144 & 2 & .002 \\
\cline { 2 - 6 } & Likelihood of having cancer 11 & -46.500 & 11.109 & 1 & .001 \\
\cline { 2 - 6 } & $\begin{array}{l}\text { Perceived Vulnerability (Chances of Getting Colon } \\
\text { Cancer at the General Population) }\end{array}$ & -43.478 & 5.065 & 1 & .024 \\
\cline { 2 - 6 } & POMS - Tense Sub-Scale & -45.922 & 9.953 & 1 & .002 \\
\hline
\end{tabular}


Table 4

Variables in the Equation

\begin{tabular}{|c|c|c|c|c|c|c|c|c|c|c|c|}
\hline & \multirow{2}{*}{$\begin{array}{c}\text { No. of } \\
\text { subjects with } \\
\text { CRC worry }\end{array}$} & \multirow[t]{2}{*}{ B } & \multirow[t]{2}{*}{ S.E. } & \multirow[t]{2}{*}{ Wald } & \multirow[t]{2}{*}{$d f$} & \multirow[t]{2}{*}{ Sig. } & \multirow[t]{2}{*}{$\operatorname{Exp}(B)$} & \multicolumn{2}{|c|}{$\begin{array}{l}95 \% \text { C.I.for } \\
\text { EXP(B) }\end{array}$} \\
\hline & & & & & & & & & & Lower & Upper \\
\hline \multirow{10}{*}{$\begin{array}{l}\text { Step } \\
11\end{array}$} & \multirow{2}{*}{ Education } & Higher & 31 & 2.220 & .688 & 10.397 & 1 & .001 & 9.206 & 2.388 & 35.489 \\
\hline & & Lower (Reference) & 29 & & & & & & & & \\
\hline & \multirow{3}{*}{$\begin{array}{l}\text { Access to } \\
\text { Gastroenterologist }\end{array}$} & $\begin{array}{l}\text { Neither easy nor } \\
\text { difficult/ Do not know }\end{array}$ & 26 & -2.201 & .817 & 7.265 & 1 & .007 & .111 & .022 & .549 \\
\hline & & Difficult & 21 & -.579 & .883 & .430 & 1 & .512 & .560 & .099 & 3.161 \\
\hline & & Easy (Reference) & 13 & & & 9.977 & 2 & .007 & & & \\
\hline & \multirow{2}{*}{$\begin{array}{l}\text { Likelihood of } \\
\text { having CRC }\end{array}$} & $\begin{array}{l}\text { Yes, There is } \\
\text { Likelihood }\end{array}$ & 51 & 2.123 & .738 & 8.275 & 1 & .004 & 8.353 & 1.967 & 35.479 \\
\hline & & Not at all (Reference) & 7 & & & & & & & & \\
\hline & \multicolumn{3}{|c|}{$\begin{array}{l}\text { Perceived Vulnerability in \% (Chances of Getting Colon } \\
\text { Cancer at the General Population) }\end{array}$} & .034 & .016 & 4.526 & 1 & .033 & 1.034 & 1.003 & 1.067 \\
\hline & \multicolumn{3}{|c|}{ POMS - Tense Sub-Scale } & 2.759 & 1.003 & 7.571 & 1 & .006 & 15.782 & 2.212 & 112.612 \\
\hline & \multicolumn{3}{|l|}{ Constant } & -7.212 & 2.055 & 12.318 & 1 & .000 & .001 & & \\
\hline
\end{tabular}


Table 5

Correlations between independent variables

\begin{tabular}{|c|c|c|c|c|c|c|c|}
\hline & & \multirow{3}{*}{$\begin{array}{r}\text { Worry } \\
1 \\
\end{array}$} & \multirow{2}{*}{$\begin{array}{r}\text { Education } \\
.166\end{array}$} & \multirow{2}{*}{$\begin{array}{c}\text { Access to } \\
\text { gastroenterologist } \\
.060\end{array}$} & \multirow{2}{*}{ 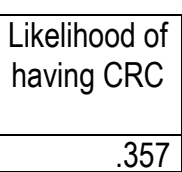 } & \multirow{2}{*}{$\begin{array}{l}\text { Perceived } \\
\text { Vulnerability to } \\
\text { CRC in \% } \\
300\end{array}$} & \multirow{2}{*}{$\begin{array}{l}\begin{array}{c}\text { POMS - } \\
\text { Tense Sub- } \\
\text { Scale }\end{array} \\
.186\end{array}$} \\
\hline \multirow{3}{*}{ Worry } & Pearson Correlation & & & & & & \\
\hline & Sig. (2-tailed) & & .055 & .494 & .000 & .001 & .032 \\
\hline & $\mathrm{N}$ & 134 & 134 & 132 & 129 & 122 & 134 \\
\hline \multirow{3}{*}{ Education } & Pearson Correlation & & 1 & -.076 & -.026 & -.155 & -.224 \\
\hline & Sig. (2-tailed) & & & .383 & .769 & .089 & .009 \\
\hline & $\mathrm{N}$ & & 136 & 133 & 129 & 122 & 134 \\
\hline \multirow{3}{*}{$\begin{array}{l}\text { Access to } \\
\text { gastro- } \\
\text { enteroloaist }\end{array}$} & Pearson Correlation & & & 1 & .094 & .154 & .215 \\
\hline & Sig. (2-tailed) & & & & .294 & .093 & .013 \\
\hline & $\mathrm{N}$ & & & 133 & 127 & 120 & 132 \\
\hline \multirow{3}{*}{$\begin{array}{l}\text { Likelihood of } \\
\text { having CRC }\end{array}$} & Pearson Correlation & & & & $1^{* *}$ & .281 & 227 \\
\hline & Sig. (2-tailed) & & & & & .002 & .010 \\
\hline & $\mathrm{N}$ & & & & 129 & 120 & 129 \\
\hline \multirow{6}{*}{$\begin{array}{l}\text { Perceived } \\
\text { Vulnerability } \\
\text { to CRC in \% } \\
\text { POMS - } \\
\text { Tense Sub- } \\
\text { Scale }\end{array}$} & Pearson Correlation & & & & & 1 & .023 \\
\hline & Sig. (2-tailed) & & & & & & .797 \\
\hline & $\mathrm{N}$ & & & & & 122 & 122 \\
\hline & Pearson Correlation & & & & & & $1^{*}$ \\
\hline & Sig. (2-tailed) & & & & & & \\
\hline & $\mathrm{N}$ & & & & & & 134 \\
\hline
\end{tabular}

**. Correlation is significant at the 0.01 level (2-tailed).

*. Correlation is significant at the 0.05 level (2-tailed). 


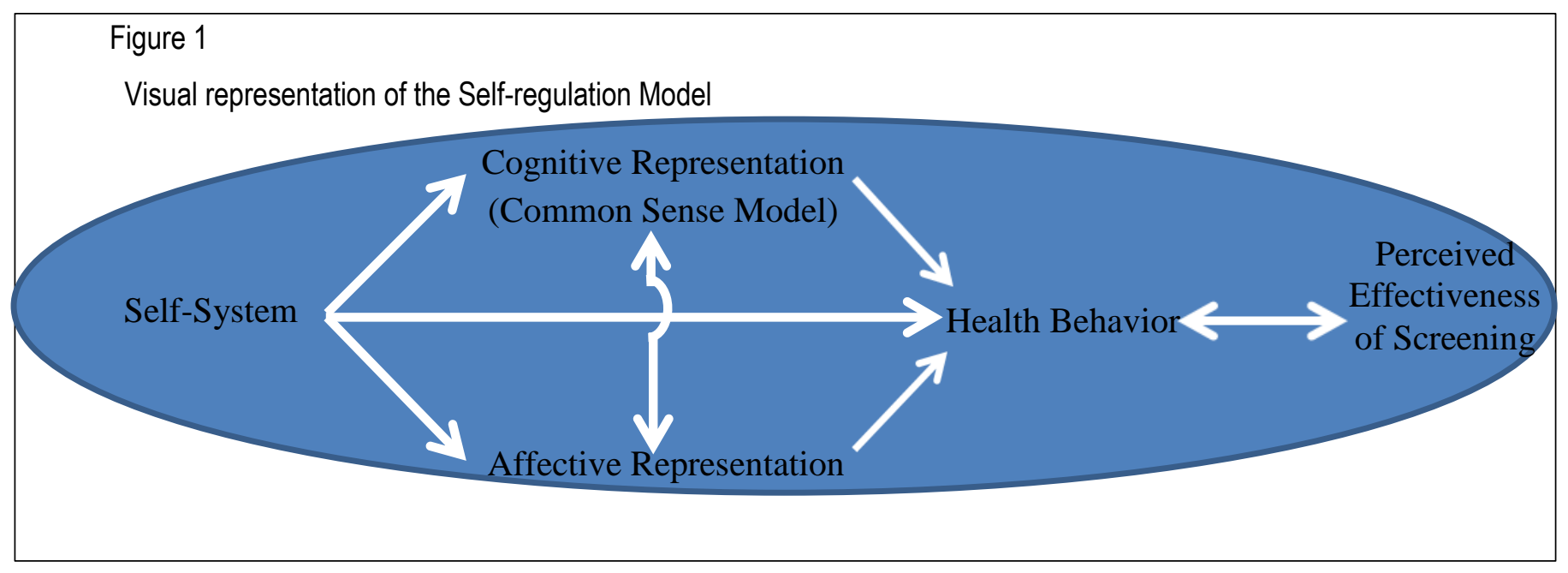




\section{Appendix 1}

\section{The Self-regulation Model Coding Scheme for Manuscript \# 1}

\section{Self-System}

(1) Demographic and Innate Factors

(2) Familial, Social, and/or Cultural Factors

(3) Health Care Provision and Health Care System

(4) Patient-Physician Interaction

Physician Trustworthiness

Physician Approach

(5) Awareness and Health Literacy

\section{Common Sense Model}

(1) Identity/Label

(2) Causes and Risk Factors

(3) Timeline

(4) Consequences

(5) Control/Cure

Preventability and Control of Colorectal Cancer

Prevention is Possible.

Prevention is Impossible

Prevention is Possible, but Difficult

Curability of Colorectal Cancer

Colorectal Cancer is Curable

Colorectal Cancer is Incurable

\section{Representation of Emotion}

Feelings about Colorectal Cancer

Fear, Discomfort, and Physical Harm

Disengagement

Feelings about Colorectal Cancer Screening

Difficult/Unpleasant Feelings

Embarrassment

Hurt/Discomfort

Perceived Inappropriateness of Screening Tests

Fear and Worry

Accepting Feelings 


\section{Appendix 2}

\section{Questionnaire for Men in Study 1}

\section{Demographic Information}

Zip Code: [In order to confirm Appalachian residence and check for rurality]

How old are you: [To confirm that the age is $\geq 50$ ]

What is your race?

1 American Indian or Alaskan Native

2 Black or African American

3 White

4 Mixed

5 Asian

6 Native Hawaiian or Other Pacific Islander

7 Other (specify)

Are you Hispanic or Latino?

$\begin{array}{ll}1 & \text { Yes } \\ 0 & \text { No }\end{array}$

Do you consider yourself to be Appalachian? [Perceived Appalachian Identity]

$\begin{array}{ll}1 & \text { Yes } \\ 0 & \text { No }\end{array}$

What is the highest level of education you have completed?

\begin{tabular}{|llll|}
\hline 0 & NONE & 93 & PRESCHOOL/KINDERGARTEN \\
94 & KINDERGARTEN & 1 & 1ST GRADE \\
2 & 2ND GRADE & 3 & 3RD GRADE \\
4 & 4TH GRADE & 5 & 5TH GRADE \\
6 & 6TH GRADE & 7 & 7TH GRADE \\
8 & 8TH GRADE & 9 & 9TH GRADE \\
10 & 10TH GRADE & 11 & 11TH GRADE \\
12 & 12TH GRADE & 13 & GED \\
& SOME COLLEGE OR & 15 & 1 OR MORE YEARS OF COLLEGE \\
14 & TECHNICAL OR TRADE SCHOOL, & OR THE TECHNICAL/TRADE \\
& BUT LESS THAN 1 YEAR & & SCHOOL, NO DEGREE \\
16 & TECHNICAL OR TRADE & 17 & ASSOCIATE DEGREE (FOR \\
& DEGREE OR CERTIFICATION & & EXAMPLE: AA, AS) \\
18 & BACHELOR'S DEGREE & 19 & MASTER'S DEGREE (FOR EXAMPLE: \\
\hline
\end{tabular}




\begin{tabular}{|lll|}
\hline (FOR EXAMPLE: BA, AB, BS, & MA,MS,MPH,MPHA,MENG,MED,MS \\
BSN) & W,MBA) \\
PROFESSIONAL DEGREE (FOR 21 & DOCTORATE DEGREE (FOR \\
20 & $\begin{array}{l}\text { EXAMPLE: MD, DDS, DVM, LLB, } \\
\text { JD) }\end{array}$ & EXAMPLE: PHD,EDD) \\
\hline
\end{tabular}

What is your annual household income?

\begin{tabular}{|c|c|}
\hline \multicolumn{2}{|c|}{ INCOME_CATEGORY } \\
\hline 1 & Less than $\$ 10,000$ \\
\hline 2 & $\$ 10,001$ to $\$ 15,000$ \\
\hline 3 & $\$ 15,001$ to $\$ 20,000$ \\
\hline 4 & $\$ 20,001$ to $\$ 25,000$ \\
\hline 5 & $\$ 25,001$ to $\$ 35,000$ \\
\hline 6 & $\$ 35,001$ to $\$ 50,000$ \\
\hline 7 & Over $\$ 50,000$ \\
\hline
\end{tabular}

\section{INSURANCE}

Are you covered by any of the following types of health insurance?

- Health insurance through your or someone else's job or union

- Health insurance bought directly by you or your family

Medicare, a government plan that pays health care bills for persons aged 65 and over, a nd some disabled people

- Medicaid

- Self pay (does not mean co-pay; usually means no insurance coverage)

$1 \quad$ Yes

$0 \quad$ No

Have you had any beer, wine, wine coolers, mixed drinks, or liquor during the past month?

$$
\begin{array}{ll}
1 & \text { Yes } \\
0 & \text { No }
\end{array}
$$

During the past month, how many days did you drink any alcoholic beverages?

Do you smoke cigarettes now?

$$
\begin{array}{ll}
1 & \text { Yes } \\
0 & \text { No }
\end{array}
$$


How many cigarettes do you smoke each day on average?

Overall, how would you rate your health in the past 4 weeks? (Perceived Health Status)

$\begin{array}{ll}1 & \text { Excellent } \\ 2 & \text { Very good } \\ 3 & \text { Good } \\ 4 & \text { Fair } \\ 5 & \text { Poor } \\ 6 & \text { Very poor }\end{array}$

\section{Survey of Colorectal Cancer \\ Structured Interview: (Audio Recorded)}

What comes to your mind when you think about colorectal cancer? (The Common Sense Model (CSM))

What are the symptoms of colorectal cancer? (Identity/Label (Symptoms) Attribute of the CSM)

What causes of colorectal cancer? (Causes Attribute if the CSM)

How might you cure colorectal cancer? (Cure/Control Attribute of the CSM)

How might you prevent colorectal cancer? (Cure/Control Attribute of the CSM)

What happens to people who have colorectal cancer? (Consequences Attribute of the CSM)

How long does colorectal cancer last? (Timeline Attribute of the CSM)

What kinds of feelings come to mind when you think about colorectal cancer? (Affective representation about $\mathbf{C R C}$ )

How would you feel if you were told you have colorectal cancer? Affective representation about CRC)

What comes to your mind when you think about colorectal cancer screening? (Cognitive representation of CRC screening)

What kinds of feelings come to mind when you think about colorectal cancer screening? (Affective representation of CRC screening) 


\section{Appendix 3}

\section{Questionnaire for Women in Study 2}

\section{Demographics:}

1. Zip code:

2. What is your date of birth?

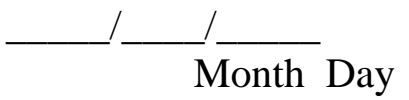

Year

3 . What is your race?

$1 \ldots$ American Indian/Alaskan Native 4

$2 \_$Black or African American 5

3 White

5 ___ Native Hawaiian/Other Pacific Islander

6 ___ Other (specify):

4. Are you Hispanic or Latino?

Yes

No

5. Do you consider yourself to be Appalachian?___ Yes __ No

6. What is the highest level of education you have completed?

0 ___ None

93___Preschool/Kindergarten

$\begin{array}{llllllllllll}\text { Grade } & 1 & 2 & 3 & 4 & 5 & 6 & 7 & 8 & 9 & 10 & 11\end{array}$

$13 \_$GED

$14 \ldots$ Some College or technical/trade school, but less than 1 year

$15 \ldots 1$ or more years of College/technical/trade school, No Degree

$16 \ldots$ Technical or Trade Degree or Certification

17 ___ Associate Degree (for example: AA, AS)

18 Bachelor's Degree (for example: BA, AB, BS, BSN)

19 Master's Degree (for example: MA, MS, MPH, MSW, MBA)

$20 \_$P__ Professional Degree (for example: MD, DDS, DVM, LLB, JD)

21___ Doctorate Degree (for example: PHD, EDD)

7. What is your marital status?

$1 \_$Married
$2 \_$Divorced
$3 \_$Widowed

$4 \ldots$ Separated

$5 \ldots$ Single, never been married

$6 \ldots$ Member of an unmarried couple

8. What is your annual household income?

$1 \_$Less than $\$ 10,000$
$2 \_\$ 10,001$ to $\$ 15,000$
$4 \_\$ 15,001$ to $\$ 20,000$
420,001 to $\$ 25,000$

$5 \_\$ 25,001$ to $\$ 35,000$

$6 \_\$ 35,001$ to $\$ 50,000$

7 O Over $\$ 50,000$

10. Of the persons living in your household including you, how many HOUSEHOLD MEMBERS:

10a. Are less than 14 years of age? member(s) 
10b. Are between 14 and 18 years of age?

member(s)

10c. Are over 18 years of age? member(s)

11. Are you currently employed for wages?

1

Fulltime

$2 \_$Parttime

$3 \_$Self-employed

$4 \quad$ Unemployed (1 year or less) 9

$6 \ldots$ Homemaker

$5 \_$Unemployed (longer than 1 year)

$7 \_$Student

$8 \_$Retired

Disabled

12. Are you covered by any of the following types of health insurance?

1 ___ Health insurance through your or someone else's job or union

2 ___ Health insurance bought directly by you or your family

3 ___ Medicare, a government plan that pays health

care bills for persons aged

65 and over, and some disabled people

4 ___ Medicaid

$5 \ldots$ Self pay (this does not mean co-pay; usually means there is no coverage)

13. Do you (or other household members) belong to a church, synagogue, or any other religious organization? Yes No

14. How often do you attend services?

$1 \_$More than Once a Week

2 Once a Week

$3 \ldots$ Several times a Month

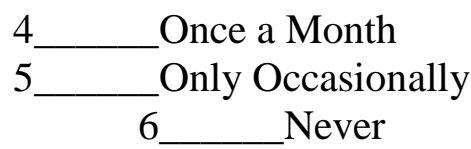

15. Have you had any beer, wine, wine coolers, mixed drinks, or liquor during the past month? Yes No

\section{Access to Gastroenterologist:}

\begin{tabular}{|l|c|c|c|c|c|c|}
\hline & $\begin{array}{c}\text { Extremely } \\
\text { Easy }\end{array}$ & $\begin{array}{c}\text { Somewhat } \\
\text { Easy }\end{array}$ & $\begin{array}{c}\text { Neither } \\
\text { Easy nor } \\
\text { Difficult }\end{array}$ & $\begin{array}{c}\text { Somewhat } \\
\text { Difficult }\end{array}$ & $\begin{array}{c}\text { Extremel } \\
\text { y } \\
\text { Difficult }\end{array}$ & $\begin{array}{c}\text { Don't } \\
\text { know }\end{array}$ \\
\hline $\begin{array}{l}\text { 1. How difficult is it for you to have } \\
\text { access to a gastroenterologist (a } \\
\text { doctor who focuses on the digestive } \\
\text { system)? }\end{array}$ & 1 & 2 & 3 & 4 & 5 & 6 \\
\hline
\end{tabular}

\section{Perceived Health Status:}

\begin{tabular}{|l|c|c|c|c|c|c|}
\hline & Excellent & $\begin{array}{c}\text { Very } \\
\text { Good }\end{array}$ & Good & Fair & Poor & $\begin{array}{c}\text { Very } \\
\text { Poor }\end{array}$ \\
\hline $\begin{array}{l}\text { Overall, how would you rate your } \\
\text { health in the past 4 weeks? }\end{array}$ & 1 & 2 & 3 & 4 & 5 & 6 \\
\hline
\end{tabular}


Religious Commitment Inventory:

\begin{tabular}{|c|c|c|c|c|c|}
\hline & Not at all & Somewhat & Moderately & Mostly & Totally \\
\hline $\begin{array}{l}\text { 1. I often read books and magazines about my } \\
\text { faith. }\end{array}$ & 1 & 2 & 3 & 4 & 5 \\
\hline $\begin{array}{l}\text { 2. I make financial contributions to my religious } \\
\text { organization. }\end{array}$ & 1 & 2 & 3 & 4 & 5 \\
\hline $\begin{array}{l}\text { 3. I spend time trying to grow in understanding } \\
\text { of my faith. }\end{array}$ & 1 & 2 & 3 & 4 & 5 \\
\hline $\begin{array}{l}\text { 4. Religion is especially important to me because } \\
\text { it answers many questions about the meaning of } \\
\text { life. }\end{array}$ & 1 & 2 & 3 & 4 & 5 \\
\hline $\begin{array}{l}\text { 5. My religious beliefs lie behind my whole } \\
\text { approach to life. }\end{array}$ & 1 & 2 & 3 & 4 & 5 \\
\hline $\begin{array}{l}6 . \text { I enjoy spending time with others of my } \\
\text { religious affiliation. }\end{array}$ & 1 & 2 & 3 & 4 & 5 \\
\hline $\begin{array}{l}\text { 7. Religious beliefs influence all my dealings in } \\
\text { life. }\end{array}$ & 1 & 2 & 3 & 4 & 5 \\
\hline $\begin{array}{l}\text { 8. It is important to me to spend periods of time } \\
\text { in private religious thought and reflection. }\end{array}$ & 1 & 2 & 3 & 4 & 5 \\
\hline $\begin{array}{l}\text { 9. I enjoy working in the activities of my } \\
\text { religious organization. }\end{array}$ & 1 & 2 & 3 & 4 & 5 \\
\hline $\begin{array}{l}\text { 10. I keep well informed about my local } \\
\text { religious group and have some influence in its } \\
\text { decisions. }\end{array}$ & 1 & 2 & 3 & 4 & 5 \\
\hline
\end{tabular}

Profile of Mood States (For measuring General Mood):

\begin{tabular}{|l|c|c|c|c|c|}
\hline & Not at all & A little bit & Moderately & Quite a bit & $\begin{array}{c}\text { Very } \\
\text { much }\end{array}$ \\
\hline 1. Tense & 1 & 2 & 3 & 4 & 5 \\
\hline 2. Angry & 1 & 2 & 3 & 4 & 5 \\
\hline 3. Worn Out & 1 & 2 & 3 & 4 & 5 \\
\hline 4. Lively & 1 & 2 & 3 & 4 & 5 \\
\hline 5. Confused & 1 & 2 & 3 & 4 & 5 \\
\hline 6. Shaky & 1 & 2 & 3 & 4 & 5 \\
\hline 7. Sad & 1 & 2 & 3 & 4 & 5 \\
\hline 8. Active & 1 & 2 & 3 & 4 & 5 \\
\hline 9. Grouchy & 1 & 2 & 3 & 4 & 5 \\
\hline 10. Energetic & 1 & 2 & 3 & 4 & 5 \\
\hline 11. Unworthy & 1 & 2 & 3 & 4 & 5 \\
\hline 12. Uneasy & 1 & 2 & 3 & 4 & 5 \\
\hline
\end{tabular}




\begin{tabular}{|l|l|l|l|l|l|}
\hline 13. Fatigued & 1 & 2 & 3 & 4 & 5 \\
\hline 14. Annoyed & 1 & 2 & 3 & 4 & 5 \\
\hline 15. Discouraged & 1 & 2 & 3 & 4 & 5 \\
\hline 16. Nervous & 1 & 2 & 3 & 4 & 5 \\
\hline 17. Lonely & 1 & 2 & 3 & 4 & 5 \\
\hline 18. Muddled & 1 & 2 & 3 & 4 & 5 \\
\hline 19. Exhausted & 1 & 2 & 3 & 4 & 5 \\
\hline 20. Anxious & 1 & 2 & 3 & 4 & 5 \\
\hline 21. Gloomy & 1 & 2 & 3 & 4 & 5 \\
\hline 22. Sluggish & 1 & 2 & 3 & 4 & 5 \\
\hline 23. Weary & 1 & 2 & 3 & 4 & 5 \\
\hline 24. Bewildered & 1 & 2 & 3 & 4 & 5 \\
\hline 25. Furious & 1 & 2 & 3 & 4 & 5 \\
\hline 26. Efficient & 1 & 2 & 3 & 4 & 5 \\
\hline 27. Full of Pep & 1 & 2 & 3 & 4 & 5 \\
\hline 28. Bad-tempered & 1 & 2 & 3 & 4 & 5 \\
\hline 29. Forgetful & 1 & 2 & 3 & 4 & 5 \\
\hline 30. Vigorous & 1 & 2 & 3 & 4 & 5 \\
\hline
\end{tabular}

POMS - Tense Sub-Scale = Mean of [Tense, Shaky, Uneasy, Nervous, Anxious]

POMS - Anger Sub-Scale = Mean of [Angry, Annoyed, Furious, Bad-tempered, Grouchy]

POMS - Depression Sub-Scale = Mean of [Sad, Discouraged, Worthless, Gloomy, Lonely]

POMS - Vigor sub-Scale $=$ Mean of [Lively, Active, Energetic, Vigorous, Full of Pep]

POMS - Fatigue sub-Scale = Mean of [Weary, Exhausted, Fatigued, Worn-out, Sluggish]

POMS - Confusion sub-Scale = Mean of [Bewildered, Confused, Forgetful, Muddled, Efficient]

Powe Fatalism Scale (For measuring Fatalism):

\begin{tabular}{|l|c|c|}
\hline & YES & NO \\
\hline $\begin{array}{l}\text { 1. I think if someone is meant to have bowel (colon) cancer, it doesn't matter what } \\
\text { kinds of food they eat, they will get colon cancer anyway. }\end{array}$ & 1 & 2 \\
\hline $\begin{array}{l}\text { 2. I think if someone has bowel (colon) cancer, it is already too late to get treated for } \\
\text { it. }\end{array}$ & 1 & 2 \\
\hline $\begin{array}{l}\text { 3. I think someone can eat fatty foods all their life, and if they are not meant to get } \\
\text { bowel (colon) cancer, they won't get it. }\end{array}$ & 1 & 2 \\
\hline 4. I think if someone is meant to get bowel (colon) cancer, they will get it no matter & 1 & 2 \\
\hline
\end{tabular}




\begin{tabular}{|c|c|c|}
\hline what they do. & & \\
\hline 5. I think if someone gets bowel (colon) cancer, it was meant to be. & 1 & 2 \\
\hline 6. I think if someone gets bowel (colon) cancer, their time to die is soon. & 1 & 2 \\
\hline $\begin{array}{l}\text { 7. I think if someone gets bowel (colon) cancer, that's the way they were meant to } \\
\text { die. }\end{array}$ & 1 & 2 \\
\hline $\begin{array}{l}\text { 8. I think getting checked for bowel (colon) cancer makes people scared that they } \\
\text { may really have colon cancer. }\end{array}$ & 1 & 2 \\
\hline $\begin{array}{l}\text { 9. I think if someone is meant to have bowel (colon) cancer, they will have colon } \\
\text { cancer. }\end{array}$ & 1 & 2 \\
\hline $\begin{array}{l}\text { 10. I think some people don't want to know if they have bowel (colon) cancer } \\
\text { because they don't want to know they may be dying from it. }\end{array}$ & 1 & 2 \\
\hline $\begin{array}{l}\text { 11. I think if someone gets bowel (colon) cancer, it doesn't matter whether they find } \\
\text { it early or late, they will still die from it. }\end{array}$ & 1 & 2 \\
\hline $\begin{array}{l}\text { 12. I think if someone has bowel (colon) cancer and gets treatment for it, they will } \\
\text { probably still die from the colon cancer. }\end{array}$ & 1 & 2 \\
\hline $\begin{array}{l}\text { 13. I think if someone was meant to have bowel (colon) cancer, it doesn't matter } \\
\text { what doctors and nurses tell them to do, they will get colon cancer anyway. }\end{array}$ & 1 & 2 \\
\hline $\begin{array}{l}\text { 14. I think if someone is meant to have bowel (colon) cancer, it doesn't matter if } \\
\text { they eat healthy foods, they will still get colon cancer. }\end{array}$ & 1 & 2 \\
\hline $\begin{array}{l}\text { 15. I think bowel (colon) cancer will kill you no matter when it is found and how it } \\
\text { is treated. }\end{array}$ & 1 & 2 \\
\hline
\end{tabular}

\section{Perceived Seriousness and deadliness of CRC:}

\begin{tabular}{|l|c|c|c|c|c|}
\hline & $\begin{array}{c}\text { Not at } \\
\text { all }\end{array}$ & $\begin{array}{c}\text { A } \\
\text { little } \\
\text { bit }\end{array}$ & Moderately & $\begin{array}{c}\text { Quite } \\
\text { a bit }\end{array}$ & $\begin{array}{c}\text { Very } \\
\text { much }\end{array}$ \\
\hline 1. How serious is colorectal cancer? & 1 & 2 & 3 & 4 & 5 \\
\hline 2. How deadly is colorectal cancer? & 1 & 2 & 3 & 4 & 5 \\
\hline
\end{tabular}

\begin{tabular}{|l|c|c|c|c|c|}
\hline & $\begin{array}{c}\text { Disagree } \\
\text { strongly }\end{array}$ & Disagree & $\begin{array}{c}\text { Neither agree } \\
\text { nor disagree }\end{array}$ & $\begin{array}{c}\text { Agree } \\
\text { Agree } \\
\text { strongly }\end{array}$ \\
\hline $\begin{array}{l}\text { 1. It is better to wait until you have a disease to do } \\
\text { anything about it. }\end{array}$ & 1 & 2 & 3 & 4 & 5 \\
\hline $\begin{array}{l}\text { 2. I try to prevent illness through a healthy } \\
\text { lifestyle. }\end{array}$ & 1 & 2 & 3 & 4 & 5 \\
\hline $\begin{array}{l}\text { 3. I try to prevent illness by having regular check- } \\
\text { ups. }\end{array}$ & 1 & 2 & 3 & 4 & 5 \\
\hline 4. I do not change my health habits unless my & 1 & 2 & 3 & 4 & 5 \\
\hline
\end{tabular}


\begin{tabular}{|l|l|l|l|l|l|}
\hline doctor says so. & & & & & \\
\hline
\end{tabular}

Cancer Worry Scale:

\begin{tabular}{|c|c|c|c|c|}
\hline & Not at all & Sometimes & Often & A lot \\
\hline $\begin{array}{l}\text { 1. During the past one week including today, how often } \\
\text { have you thought about your own chances of developing } \\
\text { colon cancer? }\end{array}$ & 1 & 2 & 3 & 4 \\
\hline $\begin{array}{l}\text { 2. During the past one week, including this time how often } \\
\text { have thoughts about your chances of getting colon cancer } \\
\text { affected your mood? }\end{array}$ & 1 & 2 & 3 & 4 \\
\hline $\begin{array}{l}\text { 3. During the past one week, how often have your } \\
\text { thoughts about your chances of getting colon cancer } \\
\text { affected your ability to perform your daily activities? }\end{array}$ & 1 & 2 & 3 & 4 \\
\hline $\begin{array}{l}\text { 4. During the past one week, how often were you } \\
\text { concerned about getting cancer? }\end{array}$ & 1 & 2 & 3 & 4 \\
\hline
\end{tabular}

\section{Perceived Vulnerability (Perceived Absolute Risk):}

1. In the general population, a woman's chances of getting colon cancer are $(0-100 \%)$ $\%$

2. What do you think the chances are that you will get colon cancer before the age of 70 ?

$(0-100 \%)$ $\%$

4. Do you feel you will be among those who get colon cancer or those who do not? Why?

Those who do not

6. How likely is it that you will have colon cancer?

1

23

Not at All Somewhat Likely Very Likely
4

Definitely

\section{Perceived Vulnerability (Perceived comparative Risk):}

3. Do you think your odds of getting colon cancer (again) are the same or different than those of other women?
Higher
The same
Lower

5. Compared with other women your age, how likely are you to get colon cancer in your lifetime?

1

Much Below

Average
2

Below

Average
3

Same/Average

Risk of Other Women
4

Above

Average
5

Much Above

Average 